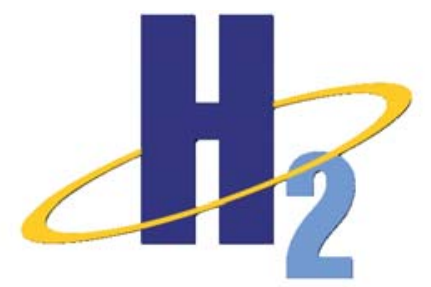

D0E Hydrogen Program

\title{
Hydrogen Generation From Electrolysis
}

\author{
Final Report for \\ DOE Award DE-FC36-04G013030 \\ March 1, 2004 to April 302008 \\ By
Steven Cohen, Stephen Porter
Oscar Chow, David Henderson
}

Principal Investigator: Stephen Porter

(203) 678-2305

sporter@protonenergy.com

Proton Energy Systems

10 Technology Drive, Wallingford CT 06492

February 28, 2009 


\section{Table of Contents}

1 PROJECT SUMMARY AND CONCLUSIONS ..........................................

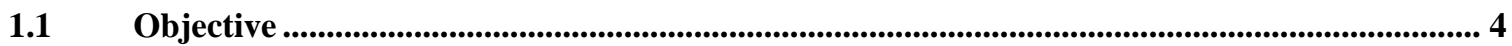

1.2 Approach............................................................................................................................... 4

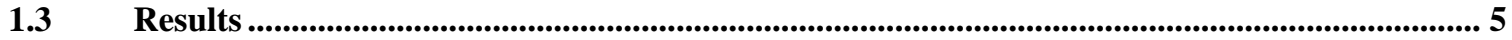

1.4 Conclusions and Future Directions.................................................................................................. 8

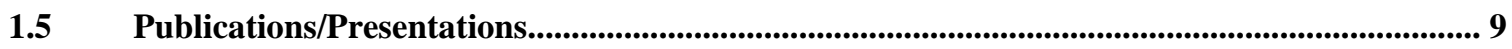

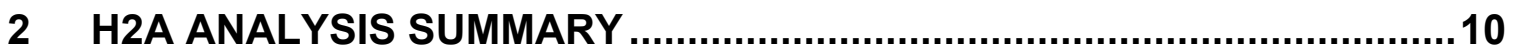

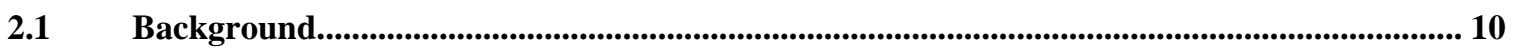

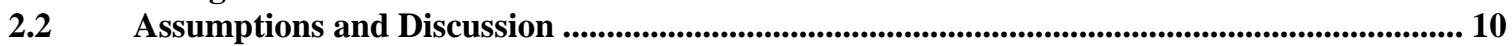

$2.3 \quad$ H2A Analysis Results ....................................................................................................................... 11

$3 \quad$ TRADE STUDY SUMMARY ..........................................................14

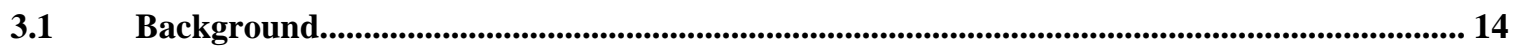

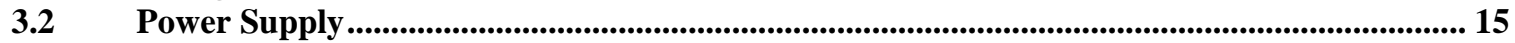

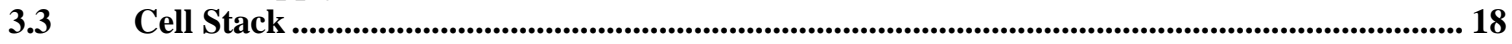

H.4 Hydrogen Separation .................................................................................................................. 20

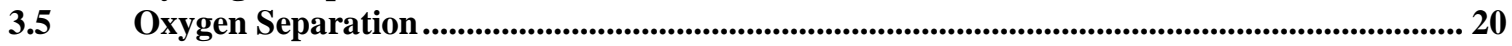

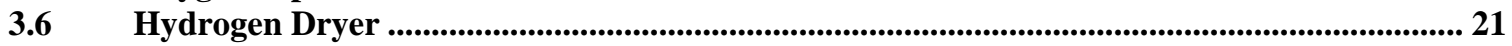

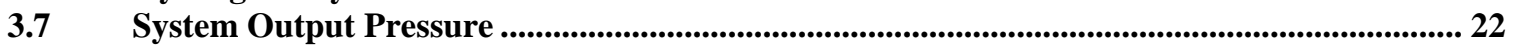

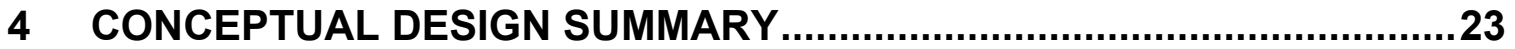

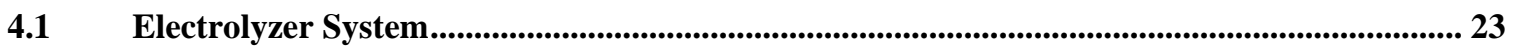

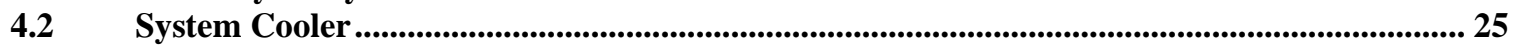

4.3 Preliminary Hazard Analysis Summary ………................................................................................... 26

5 CELL STACK COST REDUCTION STUDY ...........................................28

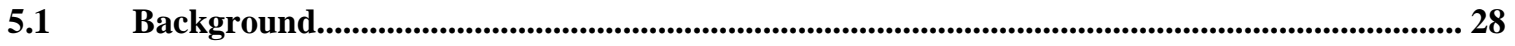

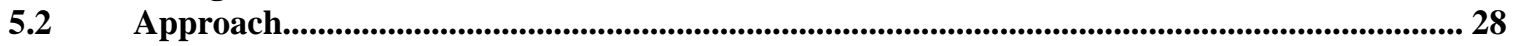

5.3 Efficiency Gains Through High Temperature Operation ............................................................... 29

5.4 Optimization of Catalyst Loading for Performance and Cost ..................................................... 31

5.5 Evaluation of Lower Cost / Higher Performance Anode Catalyst............................................... 34

5.6 Evaluation of Lower Cost / Higher Performance Ion Exchange Membranes ........................... 37

6 ELECTROCHEMICAL COMPRESSION OF HYDROGEN STUDY ............40

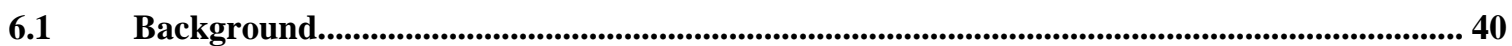

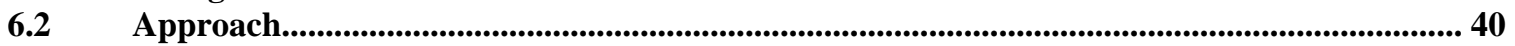

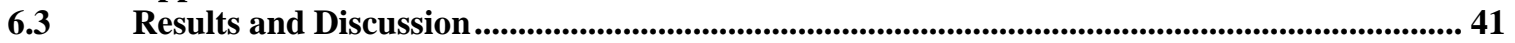

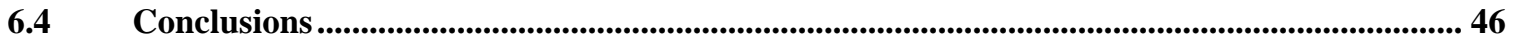

$\begin{array}{lr}\text { Proton Energy Systems } & 2 \text { of } 46\end{array}$ 


\section{Hydrogen Generation From Electrolysis}

\section{Executive Summary}

Small-scale (100-500 $\mathrm{kg} \mathrm{H}_{2}$ /day) electrolysis is an important step in increasing the use of hydrogen as fuel. Until there is a large population of hydrogen fueled vehicles, the smaller production systems will be the most cost-effective. Performing conceptual designs and analyses in this size range enables identification of issues and/or opportunities for improvement in approach on the path to $1500 \mathrm{~kg} \mathrm{H}_{2} /$ day and larger systems.

The objectives of this program are to establish the possible pathways to cost effective larger Proton Exchange Membrane (PEM) water electrolysis systems and to identify areas where future research and development efforts have the opportunity for the greatest impact in terms of capital cost reduction and efficiency improvements.

System design and analysis was conducted to determine the overall electrolysis system component architecture and develop a life cycle cost estimate. A design trade study identified subsystem components and configurations based on the trade-offs between system efficiency, cost and lifetime. Laboratory testing of components was conducted to optimize performance and decrease cost, and this data was used as input to modeling of system performance and cost.

PEM electrolysis has historically been burdened by high capital costs and lower efficiency than required for large-scale hydrogen production. This was known going into the program and solutions to these issues were the focus of the work.

The program provided insights to significant cost reduction and efficiency improvement opportunities for PEM electrolysis. The work performed revealed many improvement ideas that when utilized together can make significant progress towards the technical and cost targets of the DOE program. The cell stack capital cost requires reduction to approximately $25 \%$ of today's technology. The pathway to achieve this is through part count reduction, use of thinner membranes, and catalyst loading reduction.

Large-scale power supplies are available today that perform in a range of efficiencies, $>95 \%$, that are suitable for the overall operational goals. The balance of plant scales well both operationally and in terms of cost becoming a smaller portion of the overall cost equation as the systems get larger. Capital cost reduction of the cell stack power supplies is achievable by modifying the system configuration to have the cell stacks in electrical series driving up the DC bus voltage, thereby allowing the use of large-scale DC power supply technologies. The single power supply approach reduces cost.

Elements of the cell stack cost reduction and efficiency improvement work performed in the early stage of the program is being continued in subsequent DOE sponsored programs and through internal investment by Proton. The results of the trade study of the $100 \mathrm{~kg}$ $\mathrm{H}_{2}$ /day system have established a conceptual platform for design and development of a next generation electrolyzer for Proton. The advancements started by this program have the possibility of being realized in systems for the developing fueling markets in 2010 period. 


\section{Hydrogen Generation From Electrolysis}

\section{Project Summary and Conclusions}

\subsection{Objective}

Small-scale (100-500 $\mathrm{kg} \mathrm{H}_{2}$ /day) electrolysis is an important step in increasing the use of hydrogen as fuel. Until there is a large population of hydrogen fueled vehicles, the smaller production systems will be the most cost-effective. Performing conceptual designs and analyses in this size range enables identification of issues and/or opportunities for improvement in approach for larger systems, while maintaining robustness of cost estimates of components as they are within the size range of what is produced today.

The objectives of this program are to establish the possible pathways to cost effective larger Proton Exchange Membrane (PEM) water electrolysis systems and to identify areas where future research and development efforts have the opportunity for the greatest impact in terms of capital cost reduction and efficiency improvements. A stepping stone approach to growing PEM electrolyzer systems in generation capacity will allow incremental lessons learned to be fully incorporated, on the path to $1500 \mathrm{~kg} \mathrm{H} 2 /$ day systems.

\subsection{Approach}

The approach to performing the research for this program was to examine the PEM electrolysis system for areas of cost reduction and efficiency improvements. Early in the program (2004 and 2005), the work focused on examination of cost reductions for the cell stack and a study of electrochemical compression. In 2007, the program direction was expanded to a system (100 kg/day) level examination of cost reduction opportunities through a trade study.

\section{Cell Stack Cost Reduction Study}

The cell stack cost reduction development testing focused on four areas of potential cost reduction and efficiency improvement:

- Evaluation of Efficiency Gains Through High Temperature Operation

- Optimization of Catalyst Loading for Performance \& Cost

- Evaluation of Lower Cost / Higher Performance Catalysts

- Evaluation of Lower Cost / Higher Performance Ion Exchange Membranes

The areas were tested independently on sub-scale short stack versions of actual production hardware so comparisons to baseline data could be obtained.

\section{Electrochemical Compression Study}

The electrochemical compression study was performed on a small electrolyzer cell capable of operation at 2,400 psi. The study examined various attributes of operating the cell as a hydrogen compressor such as humidification, stoichiometry, pressure and temperature. 


\section{Hydrogen Generation From Electrolysis}

\section{$100 \mathrm{~kg} /$ day Size Unit Trade Study}

The first step was to determine an optimum functional architecture by performing trade studies. The second was to bring together the results of the sub system trade studies into a conceptual design of the system. These steps included the following:

Optimize Functional Architecture

- Perform Design Trade Studies

- Modeling And Analysis using H2A

- Perform Subsystem Testing As Appropriate For Data

Conceptual Design / Physical Architecture

- Preliminary Sizing Of Components

- Top Level Drawings

- Perform Hazard Analysis

- Obtain Relevant Budgetary Quotations

The trade studies examined several potential hardware solutions for achieving the function of the various subsystems comparing them against one another in terms of performance and cost. Leading candidate subsystems solutions were then combined and examined for performance and cost to check for interactions, both positive and negative. The best solution for one subsystem, as an example, may place a burden on the next in line resulting in a less than optimal combination. If historical performance data for a subsystem was absent, some subscale testing was performed to gain insight into the relative performance.

The conceptual design leading to a physical architecture was performed by sizing of the components and generating a representative level CAD model. This, along with the functional level documents, such as a process flow diagram, was then analyzed for hazards and mitigation techniques. Finally, quotations for the subsystems and other components including the structural enclosure, control system, and environmental controls were obtained for low quantity production (100 units per year). These costs along with estimates for cell stacks based on scale up were used in the H2A analysis.

\subsection{Results}

\section{Cell Stack Cost Reduction Study}

Progress has been made in reducing the cost of the electrolyzer cell stack through the optimization of the materials and processes used to make the membrane electrode assembly (MEA). The impact of operating temperature on overall efficiency of PEM electrolysis was evaluated, and it was shown that efficiency could be improved by as much as $5 \%$ by operating stacks at $80^{\circ} \mathrm{C}$ versus the current operating temperature of $50^{\circ} \mathrm{C}$. However, substantial modifications must be made to the balance of plant in order to operate at these temperatures and this is an area that deserves further study. It was also shown that reducing the catalyst loading on the anode by $33 \%$ and on the cathode by $25 \%$ had no impact on the performance of the MEA. This reduction in catalyst loading decreased the total cost of the catalyst by $30 \%$. 


\section{Hydrogen Generation From Electrolysis}

Future cell stack cost reduction efforts should be focused on combining the performance advantages of high temperature operation with the cost advantages of reduced catalyst loading. It should also be possible to reduce the cost of the MEA by an additional 25\% by optimizing the cell architecture in order to use thinner membrane material without any negative affects on performance or lifetime.

\section{Electrochemical Compression Study}

An alternative means to compress hydrogen gas is the use of Proton Exchange Membrane (PEM) electrochemical pump. The nature of this process could minimize maintenance requirements since there are no moving parts. The electrochemical compressor could also be an intermediate means to boost initial hydrogen inlet pressure to increase mechanical compression efficiency. As this study was limited to a first level of investigation into the principles of electrochemical compression, the potential benefits were not quantified or proven.

\section{System Analysis using H2A Model}

The H2A model was used for the system analysis to determine cost of the hydrogen produced. Details were added that allow changes in the cell stack architecture, such as membrane thickness based on current and future PEM designs. The modeling proved to be very useful in understanding how far certain aspects of the design need to be pushed beyond current capabilities to achieve the targets. This insight will help in getting the most value for the money spent on future research. Table 1.3-1, Comparison to DOE Targets, shows the initial and final results against the targets of the trade study effort. The first step in the study was to scale-up the current $12 \mathrm{~kg} /$ day electrolyzer to $100 \mathrm{~kg} / \mathrm{day}$ and estimate cost without any major changes other than size and capacity of the subsystems. The second set of results shows the progress made towards the targets at the end of the trade study addressing different components and configuration combinations.

Table 1.3-1: Comparison to DOE Targets

\begin{tabular}{|c|c|c|c|c|}
\hline Characteristics & Units & $\begin{array}{c}\text { Initial } \\
\text { 100kg/day } \\
\text { Scale-Up } \\
\text { Results }\end{array}$ & $\begin{array}{c}\text { Final } \\
100 \text { kg/day } \\
\text { Trade Study } \\
\text { Results } \\
\end{array}$ & $\begin{array}{c}\text { DOE } 1500 \\
\text { kg/day } \\
\text { Target (2012)* }\end{array}$ \\
\hline Hydrogen Cost & $(\$ / \mathrm{kg})$ & 7.86 & 5.21 & 3.70 \\
\hline $\begin{array}{l}\text { Electrolyzer Capital } \\
\text { Cost }\end{array}$ & $\begin{array}{c}(\$ / \mathrm{kg}) \\
(\$ / \mathrm{kW})\end{array}$ & $\begin{array}{c}3.30 \\
1,982 \\
\end{array}$ & $\begin{array}{c}1.74 \\
1,676 \\
\end{array}$ & $\begin{array}{c}0.70 \\
400 \\
\end{array}$ \\
\hline $\begin{array}{l}\text { Electrolyzer Energy } \\
\text { Efficiency }\end{array}$ & $\%(\mathrm{LHV})$ & 42 & 58 & 69 \\
\hline
\end{tabular}

* Targets from DOE Hydrogen, Fuel Cells \& Infrastructure Technologies Program Multi-Year Research, Development and Demonstration Plan 


\section{Hydrogen Generation From Electrolysis}

\section{Key Trade Study, Cell Stack vs. Power Supply}

The interaction of the cell stack size (active area and number of cells) versus the operational parameters of the power supply that drives it was the key trade study in terms of overall cost and efficiency of the system. High output voltage and lower current is best for power supply efficiency and cost. A large cell electrode active area allows lower current density, fewer cells, and a lower cell stack voltage; the reduced cell count is best for lowering the cost of the cell stack. A new topology for Proton, which has one power supply driving multiple cell stacks in electrical series, was determined to be the best middle ground solution.

\section{Power Supply Trade Study}

Two concepts for power supplies were selected as potential candidates for future research and development projects. Insulated Gate Bipolar Transistor (IGBT) based technology as the primary, and Semi-Conductor Rectifier (SCR) based DC motor drives as the fallback concept if unexpected problems with the IGBT are found. When incorporated in a system configured to meet the target price, the IGBT provides the highest overall efficiency. IGBT also provides the highest quality power with no additional equipment, and it is the most suitable to adaptation to receive DC input power from renewable energy sources.

IGBT technology based power supplies are the preferred technology for conversion of wind power to the grid. It is likely that the costs will fall and the reliability and performance will improve for this technology power supply. The scale-up of the power supplies required for conversion of wind power going forward also complements the scale-up to much larger electrolysis systems.

\section{Cell Stack Trade Study}

Two cell stack architectures were examined as part of the trade study. One is a round plastic frame design that is the current production model. The second uses solid Titanium (Ti) bipolar plates, which Proton has developed as prototypes with very promising results. The individual design parameters of the two cell stacks were not examined as part of the trade study, rather the performance and estimated cost of scaled up versions were used comparatively in the analysis. The results of the trade study comparing these two designs indicates that the bipolar plate design offers much greater overall system efficiency, as there are less interfaces, but the solid Ti plates are expensive. Further research and development of composite type plates is warranted.

\section{Phase Separator Testing}

Preliminary phase separation systems were tested, but further work is needed for optimization. In particular, the bench-top proof-of-concept system for hydrogen-water separation looks promising, but the single vessel oxygen-water separator tested is too large and is not a likely candidate. Both industrial solutions and modifications to the initial systems tested will be investigated as part of future research and development.

\section{Compression Trade Study}

The system was analyzed as part of the trade study is proposed to run at a system pressure of $30 \mathrm{bar}$ (435 psi), but higher pressures should be kept open for consideration. 


\section{Hydrogen Generation From Electrolysis}

It is unlikely to be a cost advantage in going to lower pressure, in that the cost of downstream compression is higher over the life of the system, and the cell stack cost reduction from lower operating pressure is uncertain. There is a benefit to higher system operating pressure in that the gas coming from the cell stack has a lower water content, which reduces losses in the drying process. For the $100 \mathrm{~kg} /$ day size system studied, it was calculated that increasing the electrolyzer system pressure to 55 bar (800 psi) will drop the compressor capital cost by $\$ 16 \mathrm{~K}$, and the annual electrical power cost by $\$ 5 \mathrm{~K}$. Further work on establishing the cost of higher system pressure electrolyzer is needed to make the final decision.

\section{Conceptual Design}

The main result of the conceptual design was a CAD layout of the system broken into four major compartments. The breakup of the compartments was driven by the results of a hazard analysis, each compartment with the potential for its own types of hazards. An example is the cell stack power supplies. There is a significant arc flash hazard with an electrical feed approaching 300kW. For the cell stacks and pressurized hydrogen components, however there is the potential for leaks resulting in a combustible mixture hazard. Compartmentalizing the design into controls, power, hydrogen, and oxygen/water subsystems allows different mitigation techniques specific to the potential hazard used in a cost effective and safe manner.

Many of the subsystems sized for $100 \mathrm{~kg} \mathrm{H}_{2}$ /day are essentially expansions of the current $12 \mathrm{kgH}_{2}$ /day production system. Going to $500 \mathrm{~kg} \mathrm{H}_{2}$ /day and larger will require significant changes in approach. For example, the phase separators may need to be large pressure vessels to handle the two-phase oxygen/water flows approaching $250 \mathrm{gpm}$. In addition, with five times the power supply and cell stacks, the system will probably not be suited to building and shipping in a single compact enclosure. The $500 \mathrm{~kg} \mathrm{H}_{2} / \mathrm{day}$ implementation will more likely be separate modules interconnected on site similar to other small-scale chemical processing plant equipment is today. The modules could be self-contained enclosures or be skid mounted installed in a container or small building onsite.

\subsection{Conclusions and Future Directions}

The program provided insights to significant cost reduction and efficiency improvement opportunities for PEM electrolysis. The work performed revealed many improvement ideas that when utilized together can make significant progress towards the technical and cost targets of the DOE program. The cell stack capital cost requires reduction to approximately $25 \%$ of today's technology. The pathway to achieve this is through part count reduction, use of thinner membranes, and catalyst loading reduction. Capital cost reduction of the cell stack power supplies is achievable by modifying the system configuration to have the cell stacks in electrical series driving up the DC bus voltage allowing the use of large-scale DC power supply technologies. The single power supply approach reduces cost.

The biggest opportunity for cost savings beyond that of the system examined is by increasing system efficiency to further reduce electricity use. Some of the same improvements required to lower capital cost for the cell stack, parts count and thinner 


\section{Hydrogen Generation From Electrolysis}

membranes, are also required to improve efficiency so a double benefit can be realized from future research in these areas.

Elements of the cell stack cost reduction and efficiency improvement work performed in the early stage of the program has been carried on in subsequent DOE sponsored programs and through internal investment by Proton. The results of the trade study of the $100 \mathrm{~kg} /$ day system have established a conceptual platform for design and development of a larger size electrolyzer for fueling applications by Proton. The advancements started by this program have the possibility of being realized in systems for the developing hydrogen fueling markets in the near term.

\subsection{Publications/Presentations}

T. Maloney, S. Porter, Hydrogen Generation from Electrolysis, Proceedings of the DOE Hydrogen Program Annual Merit Review and Peer Evaluation Meeting, Philadelphia $P A, 2004$

S. Porter, D. Henderson, O. Chow, Hydrogen Generation from Electrolysis, Proceedings of the DOE Hydrogen Program Annual Merit Review and Peer Evaluation Meeting, Arlington VA, 2005

L. Moulthrop, E. Anderson, O. Chow, R. Friedland, S. Porter, M. Schiller, S. Szymanski, Commercializing Larger PEM-based Hydrogen Generators for Energy and Industrial Applications; Proceedings of the NHA Annual Hydrogen Conference, San Antonio TX, 2007.

S. Cohen, S. Porter, Hydrogen Generation from Electrolysis, Proceedings of the DOE Hydrogen Program Annual Merit Review and Peer Evaluation Meeting, Arlington VA, 2007

L. Moulthrop, M. Zoeller, E. Anderson, S. Porter, Commercial Progress, PEM-Based Hydrogen Generators For Fueling; Proceedings of the NHA Annual Hydrogen Conference, Sacramento CA, 2008.

S. Porter, S. Cohen, Hydrogen Generation from Electrolysis, Proceedings of the DOE Hydrogen Program Annual Merit Review and Peer Evaluation Meeting, Arlington VA, 2008 


\section{Hydrogen Generation From Electrolysis}

\section{H2A Analysis Summary}

\subsection{Background}

A spreadsheet was developed to model the cost and performance of a PEM electrolyzer, incorporating cell stack performance models, power supply parameters, and balance of plant costs. These were integrated with the H2A model. The parameters that were used as input to the H2A tool are shown in Figure 2.1-1: System Model Flow Chart.

By varying parameters such as power supply output voltage and current density of the cell stack, the capital cost of the electrolyzer, the efficiency of the electrolyzer, and the H2A $\$ / k g$ of hydrogen could be calculated.

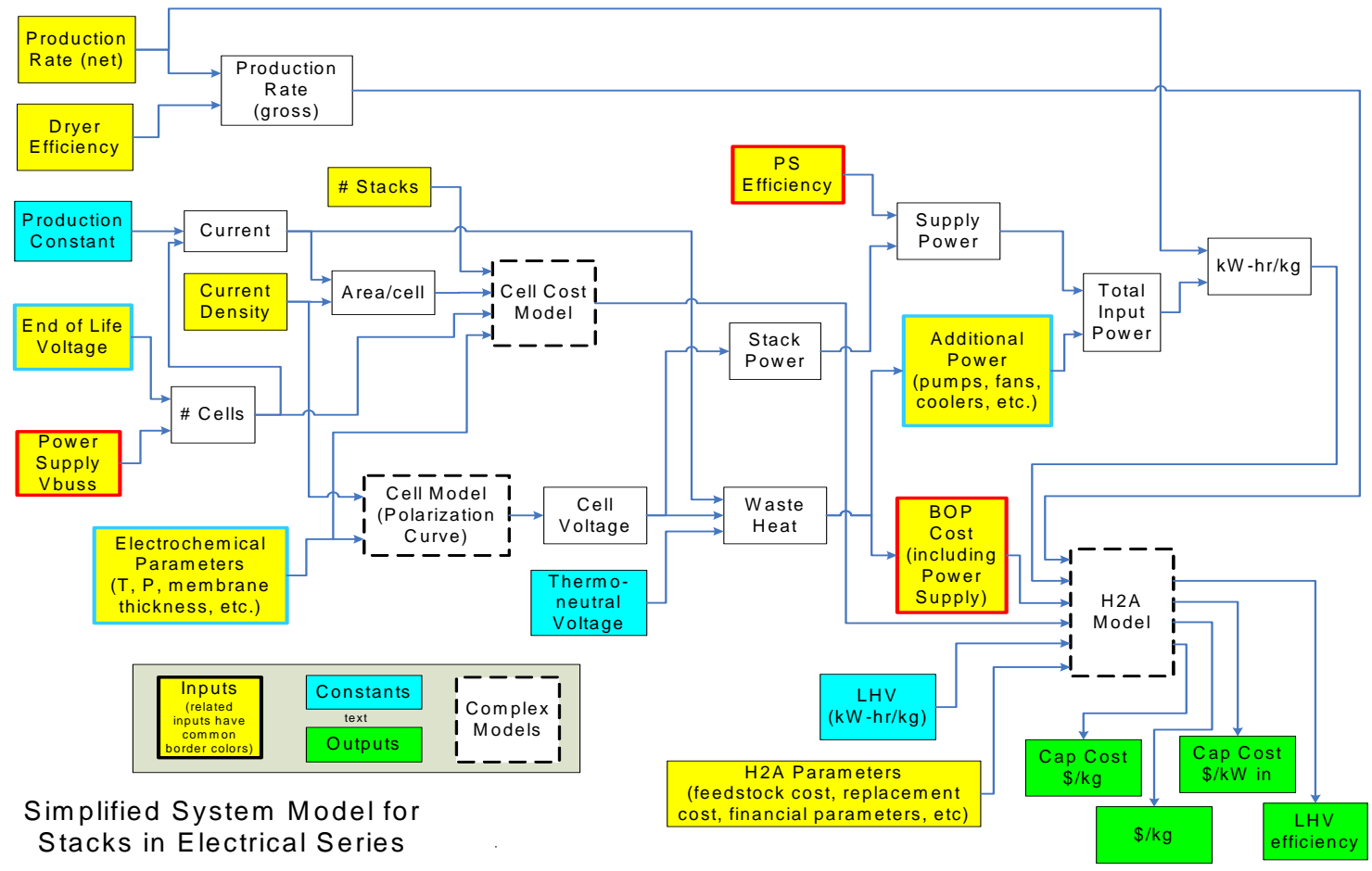

Figure 2.1-1: System Model Flow Chart

\subsection{Assumptions and Discussion}

The electrolyzer system model used in conjunction with the H2A model was developed and refined over the course of the project. The electrolyzer system analyzed is represented in a simplified form in figure 3.1-1, PEM Electrolyzer Simplified Block Diagram. Cell stack cost and performance models were initially developed as part of the program in the 2004 - 2005 timeframe. Early in the trade study portion of the project, a simplified version of the model was used to examine the cost and efficiency of a wide variety of power supplies. The focus was to determine the companion cell stack active area size and number of cells that yielded the minimum cost per kilogram of hydrogen. 


\section{Hydrogen Generation From Electrolysis}

As the study progressed, more details were incorporated into the model including pull down menus for the various technologies of power supplies, size and configuration of cell stack, cell stack capital replacement interval and cost. The assumptions associated with the H2A portion of the model are given in Figure 2.2-1: H2A Model Assumptions. These were selected based on the early deployment of $100 \mathrm{~kg} \mathrm{H}_{2} /$ day systems for demonstrations such as captive fleet fueling.

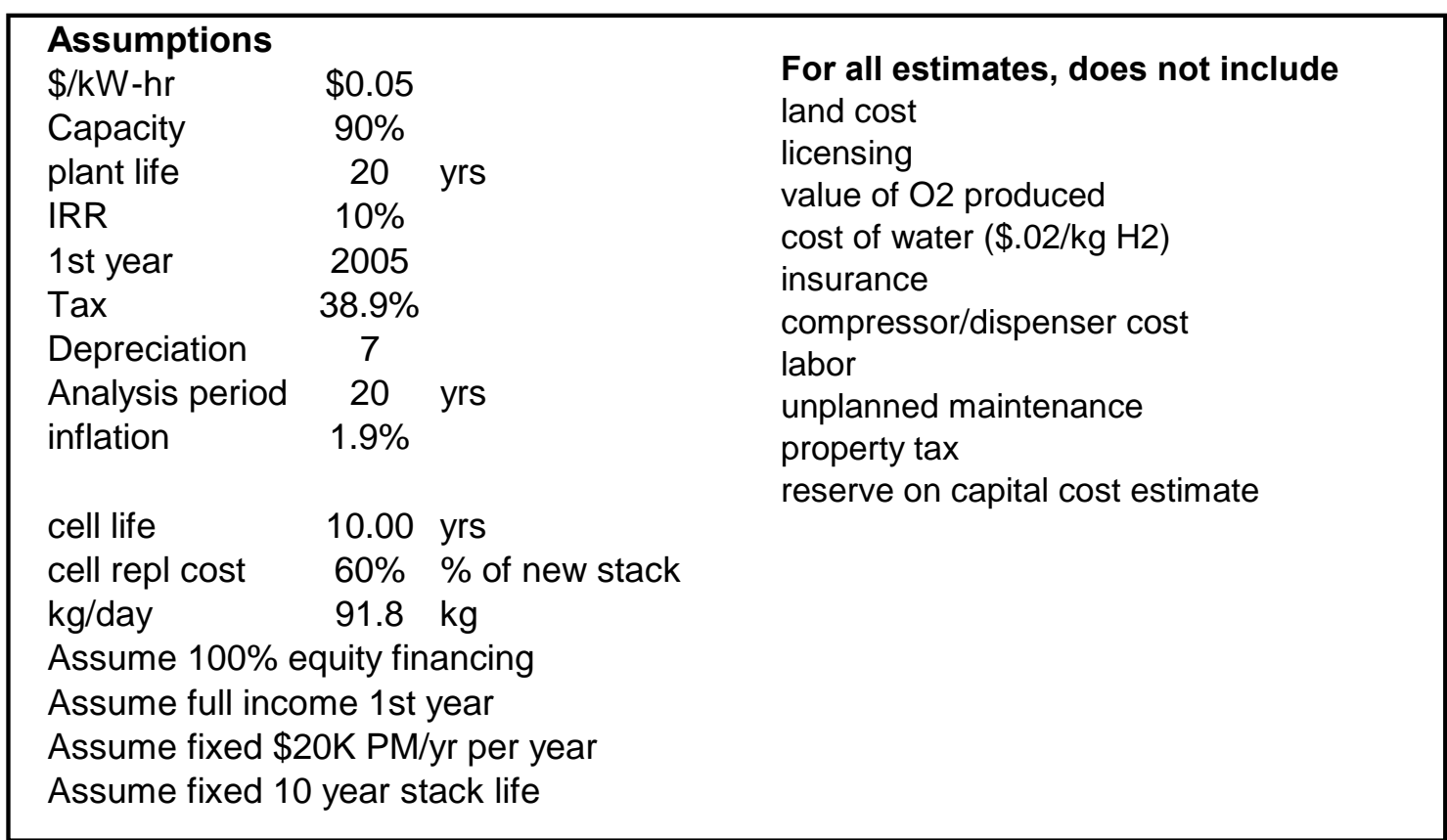

\section{Figure 2.2-1: H2A Model Assumptions}

\subsection{H2A Analysis Results}

One of the most useful outputs of the analysis was a comparison of how the various power supplies and cell stack combinations in the study drove capital cost and efficiency for a given operating current density. The total output of $100 \mathrm{~kg} \mathrm{H}_{2} /$ day was fixed resulting in a system cost curve for each type of power supply examined in the study at specific current densities. The resulting efficiency vs. system cost is shown in Figure 2.2-2.

Each point on a line corresponds to a current density value, with higher current density on the left. The lower current densities to the right represent larger cell stack total active areas, and the higher capital cost associated with them. The chart can be used to determine cell stack size for a given initial capital cost that is acceptable to the target market. In cases where the local electricity rates and resulting operational costs are more important to the end user, a higher initial capital cost is the result. In all cases, the IGBT power supply configuration yields the lowest capital cost for a given current density operating point. 


\section{Hydrogen Generation From Electrolysis}

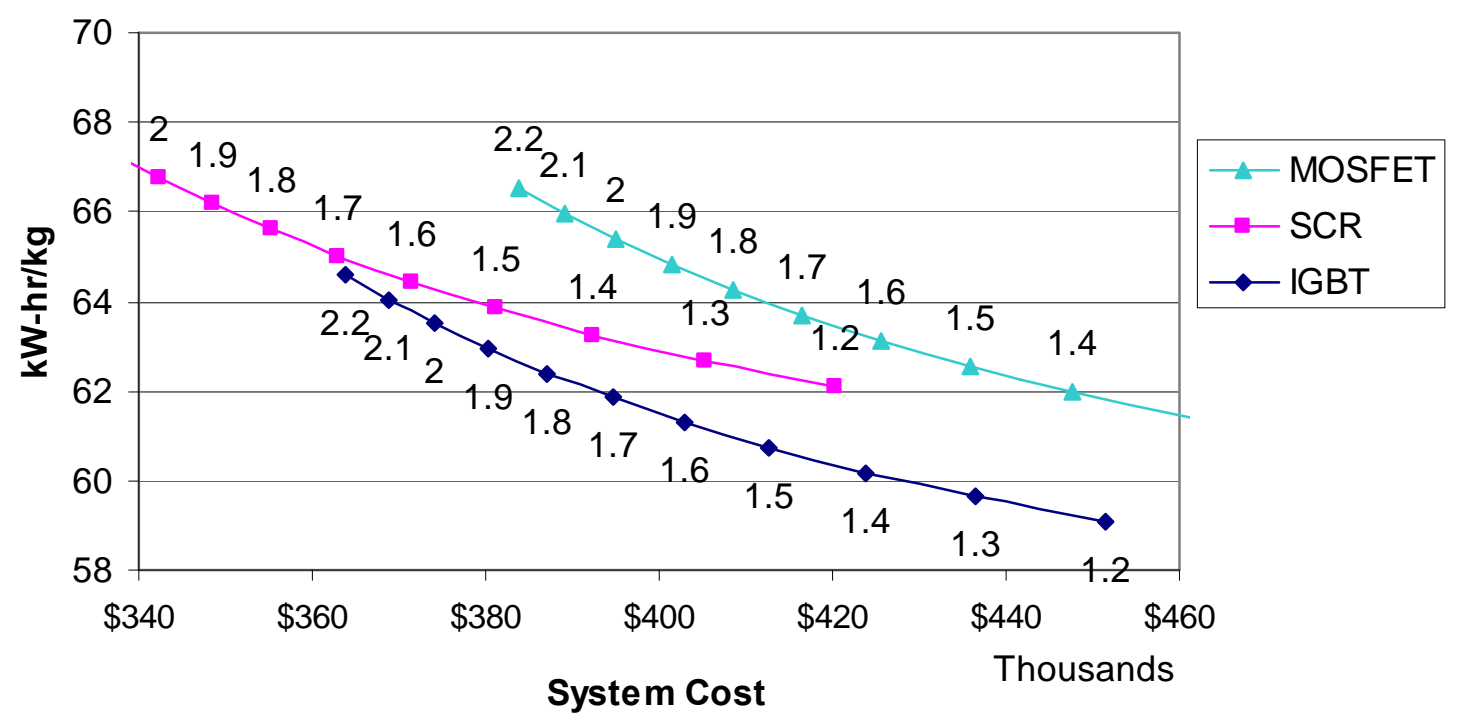

Figure 2.3-1: System Cost vs. Efficiency

The model was utilized to examine a wide variety of system components and configurations topologies primarily varying the two leading cost drivers, the cell stack and power supplies. Performance of a complete standalone system, including cooler and DI water system, is shown in Table 2.3-1: Comparison to DOE targets. The table shows the initial and final results against the targets of the trade study effort. The first step in the study was to scale-up the current $12 \mathrm{~kg} /$ day electrolyzer to $100 \mathrm{~kg} /$ day and estimate cost without any major changes other than size and capacity of the subsystems. The second set of results shows the progress made towards the targets at the end of the trade study.

Table 2.3-1: Comparison to DOE Targets

\begin{tabular}{|l|c|c|c|c|}
\hline Characteristics & Units & $\begin{array}{c}\text { Initial } \\
100 \mathrm{~kg} / \text { day } \\
\text { Scale-Up } \\
\text { Results }\end{array}$ & $\begin{array}{c}\text { Final } \\
100 \mathrm{~kg} / \text { day } \\
\text { Trade Study } \\
\text { Results }\end{array}$ & $\begin{array}{c}\text { DOE 1500 } \\
\mathrm{kg} / \text { day } \\
\text { Target } \\
(2012)^{*}\end{array}$ \\
\hline Hydrogen Cost & $\mathbf{( \$ / \mathrm { kg } )}$ & 7.86 & 5.21 & 3.70 \\
\hline $\begin{array}{l}\text { Electrolyzer Capital } \\
\text { Cost }\end{array}$ & $\mathbf{( \$ / \mathrm { kg } )}$ & 3.30 & 1.74 & 0.70 \\
$\mathbf{( \$ \mathrm { kW } )}$ & 1,982 & 1676 & 400 \\
\hline $\begin{array}{l}\text { Electrolyzer Energy } \\
\text { Efficiency }\end{array}$ & $\%(\mathrm{LHV})$ & 42 & 58 & 69 \\
\hline
\end{tabular}

* Targets from DOE Hydrogen, Fuel Cells \& Infrastructure Technologies Program Multi-Year Research, Development and Demonstration Plan

The discrepancy between the DOE targets and the Proton estimate is due largely to the size of the target system vs. that analyzed. In terms of near term market acceptance, the 


\section{Hydrogen Generation From Electrolysis}

capital cost and cost of the hydrogen produced is in line with near term market expectations for this size system in low volumes. Proton is continuing the work on a system of this size with target deployment in late 2010.

An additional way of examining the system was to perform simplified analysis ommiting finical variables such as taxes, depreciation, working capital, or inflation. The sum of initial purchase cost plus operating costs over 20 years divided by $\mathrm{kg}$ of $\mathrm{H} 2$ produced over 20 years was used to examine basic life cycle costs. The distribution of cost over the life of the system is shown in Figure 2.3-2: Life Cycle Cost Analysis results. The results show that efficiency is the main driver over the long term and research should continue in this area. The maintenance costs need to be addressed in future designs eliminating the need through increased reliability and robustness of the design.

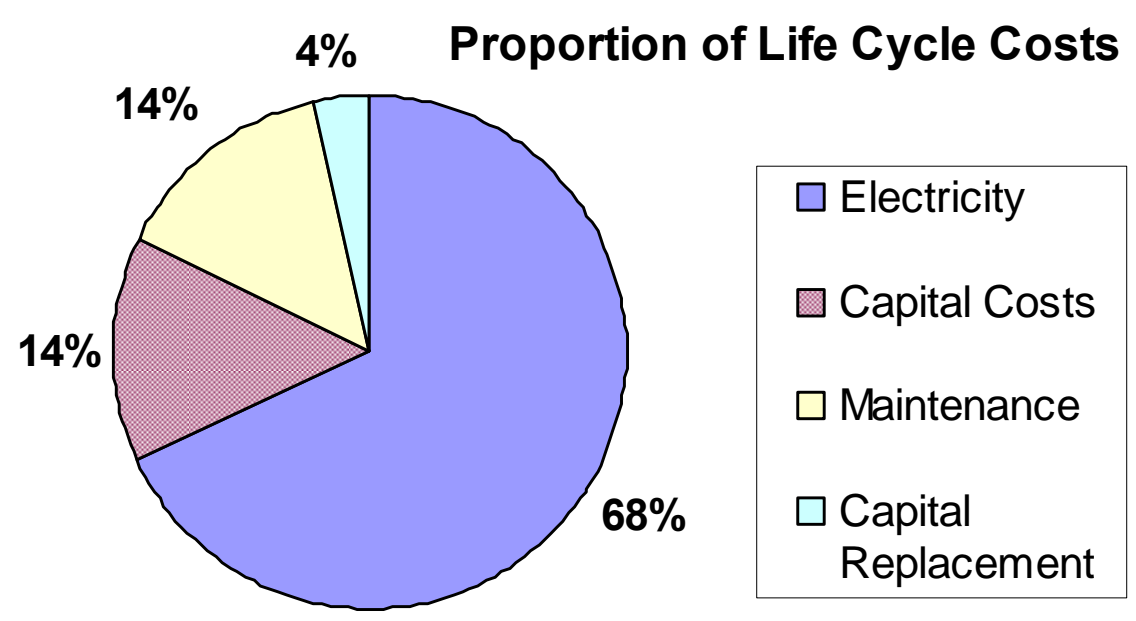

Figure 2.3-2: Life Cycle Cost Analysis Results 


\section{Hydrogen Generation From Electrolysis}

\section{Trade Study Summary}

Each of the subsystems and components that make up the $100 \mathrm{~kg} \mathrm{H}_{2} /$ day PEM electrolyzer were considered to the extent required based on the impact on the overall capital cost and performance of the system. The major subsystem and operational parameters trade studies are summarized in this section.

\subsection{Background}

The study focuses on the design of a $100 \mathrm{~kg} \mathrm{H}_{2}$ /day hydrogen fuel generating system. The interconnection of the system elements is shown in Figure 3.1-1: PEM Electrolyzer Simplified Block Diagram. The function of the basic elements is outlined below.

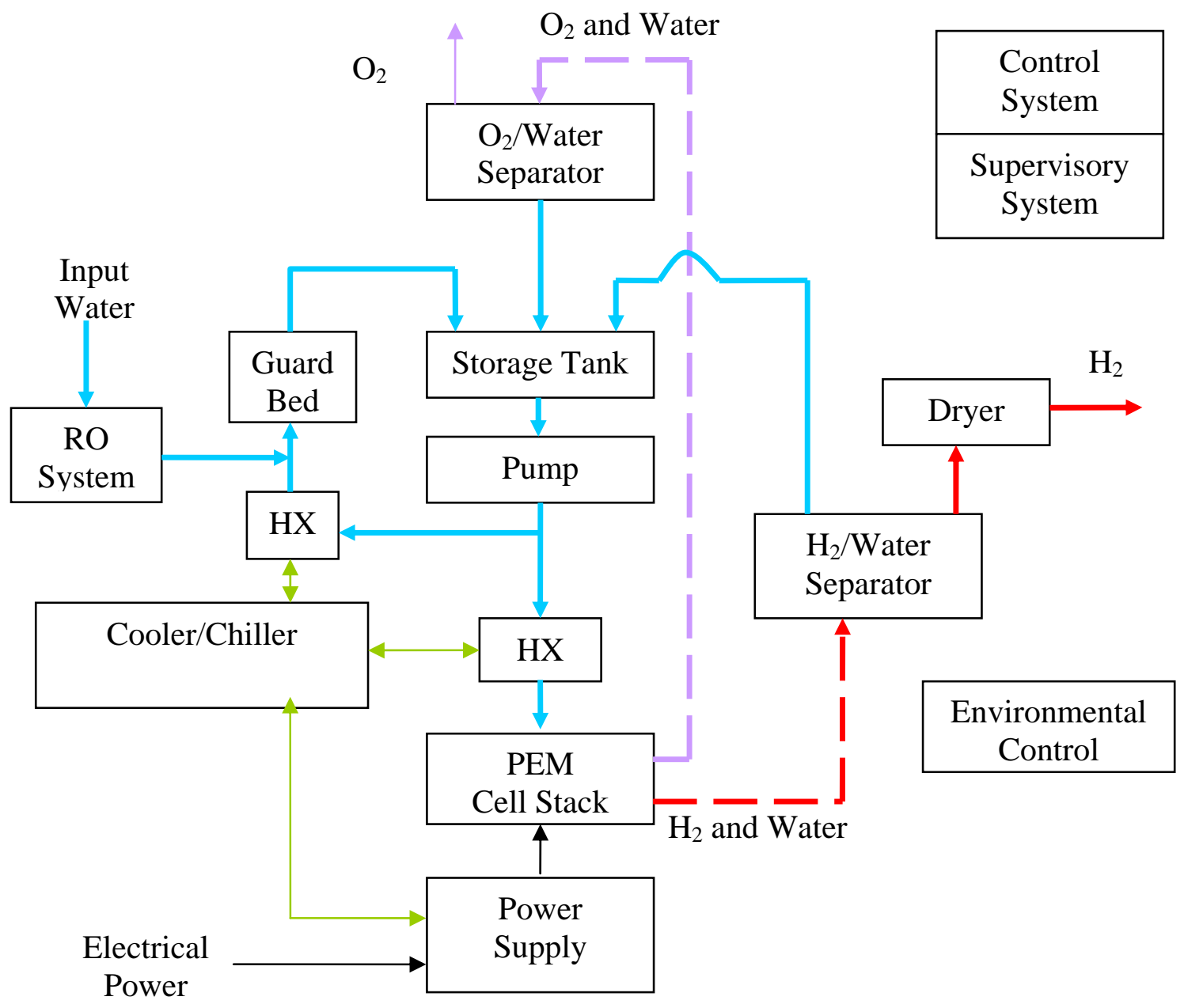

Figure 3.1-1: PEM Electrolyzer Simplified Block Diagram

- The RO system cleans input water to the required water quality.

- The guard bed removes most dissolved ionic contaminants, polishing the water circulated through the system as it operates. 


\section{Hydrogen Generation From Electrolysis}

- The power supply converts AC input electrical power to the DC current needed for electrolysis.

- The Proton Exchange Membrane cell stack splits the water into hydrogen and oxygen. Both output steams contain liquid water.

- The pump re-circulates the water throughout the system.

- The storage tank holds the water that is used for cooling the cell stacks and the feedstock for the electrolysis process.

- The $\mathrm{O}_{2} /$ Water separator removes the oxygen and returns the water to the system.

- The $\mathrm{H}_{2} /$ Water separator removes liquid water from the hydrogen and returns it to the system; hydrogen flows to the dryer.

- The $\mathrm{H}_{2}$ dryer removes remaining water vapor from the hydrogen.

- The control system provides for fully automated operation and user input.

- The supervisory system halts operations when selected system parameters exceed allowable limits.

- The environmental control system maintains the internal temperature and, where applicable, fugitive gas concentrations within acceptable ranges, enabling outdoor siting and safe operation.

\subsection{Power Supply}

A major portion of the trade study effort was focused on the overall relationship of power supply and cell stacks. The first step was to identify various $300 \mathrm{~kW}$ AC/DC power supplies suitable for a PEM electrolyzer over a wide range of output buss voltages. The next step was to create a cell stack cost and performance model that takes input buss voltage as one of the parameters.

The study identified eight converter suppliers that either had a commercially available $300 \mathrm{~kW}$ product or had the technical capabilities to develop a custom converter for the application. The requests for quote specifically left the converter output voltage as a variable to allow the suppliers maximum flexibility to reduce cost and maximize efficiency. Each supplier quoted a $300 \mathrm{~kW}, 480 \mathrm{~V}$ nominal 3-phase to programmable constant current converter, in quantities of 10 converters per year.

Based on the results of the initial trade study the best power supply was a Silicon Controlled Rectifier (SCR) based DC motor drive with very low cost and high efficiency. The second-best supply option was an Insulated Gate Bipolar Transistor (IGBT) based power supply. The IGBT supply has higher cost and lower efficiency than the SCRsupply, but has ancillary benefits including a familiar steady DC output current and an intermediate DC bridge suitable for direct connection to green-energy sources like wind turbines and photo-voltaic arrays.

Because the SCR DC motor drive appeared to be the best option, but pulsed current output was a new factor, Proton purchased a small SCR DC motor drive supply capable of driving a current production $12 \mathrm{~kg} /$ day hydrogen generator. This sub-scale test set-up is shown in Figure 3.2-1: DC Motor Drive Test Setup. 


\section{Hydrogen Generation From Electrolysis}

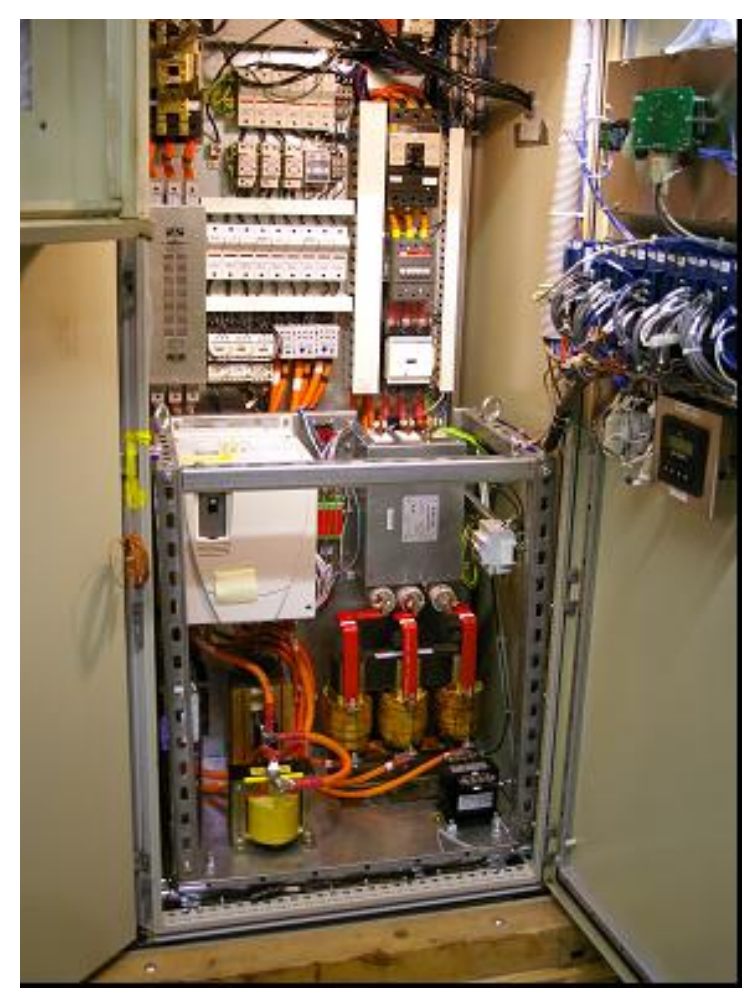

Figure 3.2-1: DC Motor drive Test Setup

The testing was performed with the cell stacks in series to match the voltage output of the DC Motor drive. At first one cell stack was driven, then two in series, finally all three in series. This test showed there are no complications operating three cell stacks in series in electrical terms over a short run time. The instantaneous voltages of each cell stack balance as manufacturing tolerances would predict. The voltage across one cell followed the current pulses as it did across the entire three stacks in series. Figure 3.2-2 shows the uniformity of the waveforms across all the cell stacks (left) as compared to one cell (right).
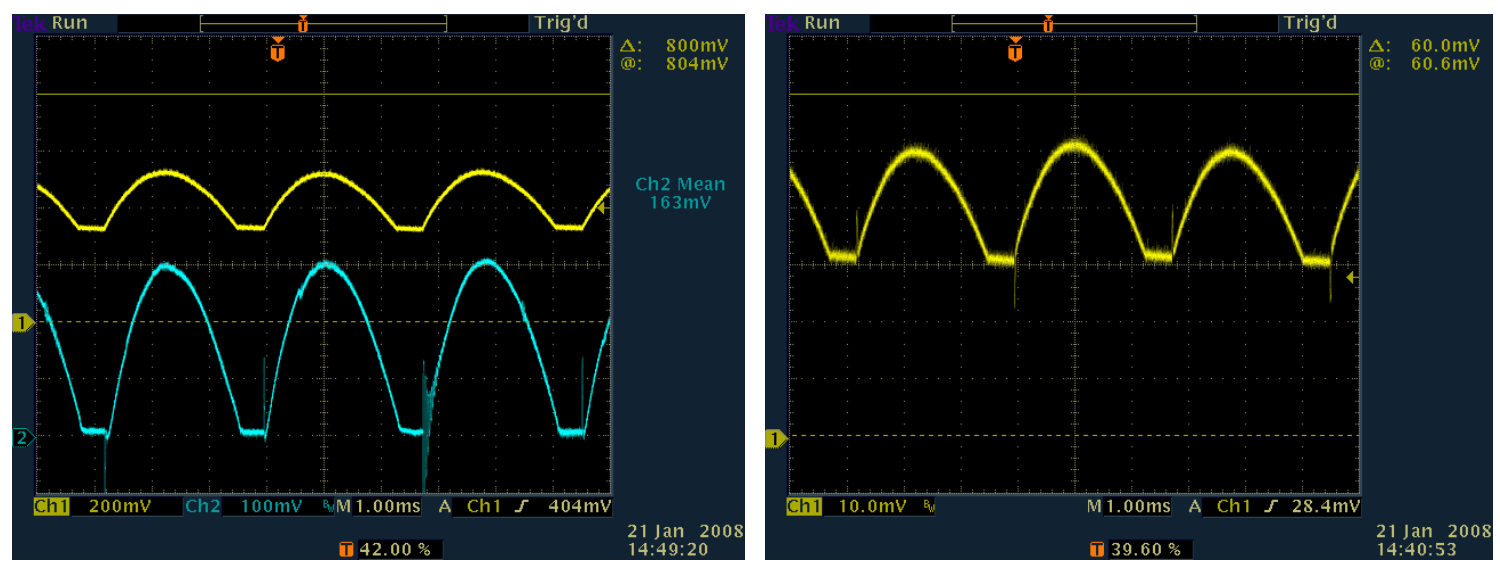

Figure 3.2-2 Voltage and Current Waveforms of DC Motor Drive Tests 


\section{Hydrogen Generation From Electrolysis}

Though the testing used the same average current as Proton's traditional supply, the SCR current pulses reached a peak current density of $3.4 \mathrm{~A} / \mathrm{cm} 2$. The effect of this peak current density on cell stack performance was tested.

The total power consumption of the $12 \mathrm{~kg} /$ day hydrogen generator was measured while generating hydrogen, both with the DC Motor drive-supply and with the traditional MOSFET switch-mode power supplies. The team was surprised to learn that the DC Motor drive-supply required $8.8 \%$ more energy (kWhr) to generate a kg of hydrogen as shown in Table 3.2-1.

Table 3.2-1: Comparison of Power Consumption SCR Motor Drive vs. MOSFET

\begin{tabular}{|c|c|c|c|c|c|}
\hline SCR Motor Drive & & & & & \\
\hline Run-Time & kWhr & SCFH & $\begin{array}{c}\text { System } \\
\text { Temp }\end{array}$ & \multirow{2}{*}{$\begin{array}{c}\text { Power } \\
\text { Consumption }\end{array}$} & \\
\hline $3 \mathrm{hrs} 20$ minutes & 142.33 & 760 & 50 & & \\
\hline $1 \mathrm{hr}$ & 42.7 & 228 & 50 & 18.7 & \multirow{2}{*}{$\begin{array}{l}\mathrm{kWh} / 100 \mathrm{SCFH} \\
\mathrm{kWhr} / \mathrm{kg}\end{array}$} \\
\hline & & & & 74.3 & \\
\hline \multicolumn{6}{|l|}{ MOSFET Supplies } \\
\hline Run-Time & kWhr & SCFH & $\begin{array}{c}\text { System } \\
\text { Temp }\end{array}$ & \multirow{2}{*}{$\begin{array}{c}\text { Power } \\
\text { Consumption }\end{array}$} & \\
\hline $3 \mathrm{hrs}$ & 120.7 & 701 & 50 & & \\
\hline $1 \mathrm{hr}$ & 40.23 & 233.67 & 50 & 17.2 & \multirow{2}{*}{$\begin{array}{l}\mathrm{kWh} / 100 \mathrm{SCF} \\
\mathrm{kWhr} / \mathrm{kg}\end{array}$} \\
\hline & & & & 68.3 & \\
\hline
\end{tabular}

Next, cell stack models were used to predict the $\mathrm{kWhr} / \mathrm{kg}$ production efficiency based on different current densities. Low current densities of about $0.5 \mathrm{~A} / \mathrm{cm} 2$ convert electrical power to hydrogen very efficiently ( $45.5 \mathrm{kWhr} / \mathrm{kg}$ ), but higher current densities of $3.4 \mathrm{~A} / \mathrm{cm} 2$ convert electrical power to hydrogen much less efficiently (65.9 kWhr $/ \mathrm{kg})$. As each current pulse from the drive-supply pushes-through the stack's active area, the stack passes from high efficiency, to low efficiency, and back to high efficiency.

By comparing the efficiency against the traditional steady current of the production MOSFET supplies (55.3 kWhr/kg), the team found a net efficiency loss of $6.5 \%$. The difference between the calculated efficiency and the measured efficiency of the current pulse style DC motor drive might be due to the age of the cell stacks used in the test. The calculated values are illustrated in Figure 3.2-3 for one current pulse. 


\section{Hydrogen Generation From Electrolysis}

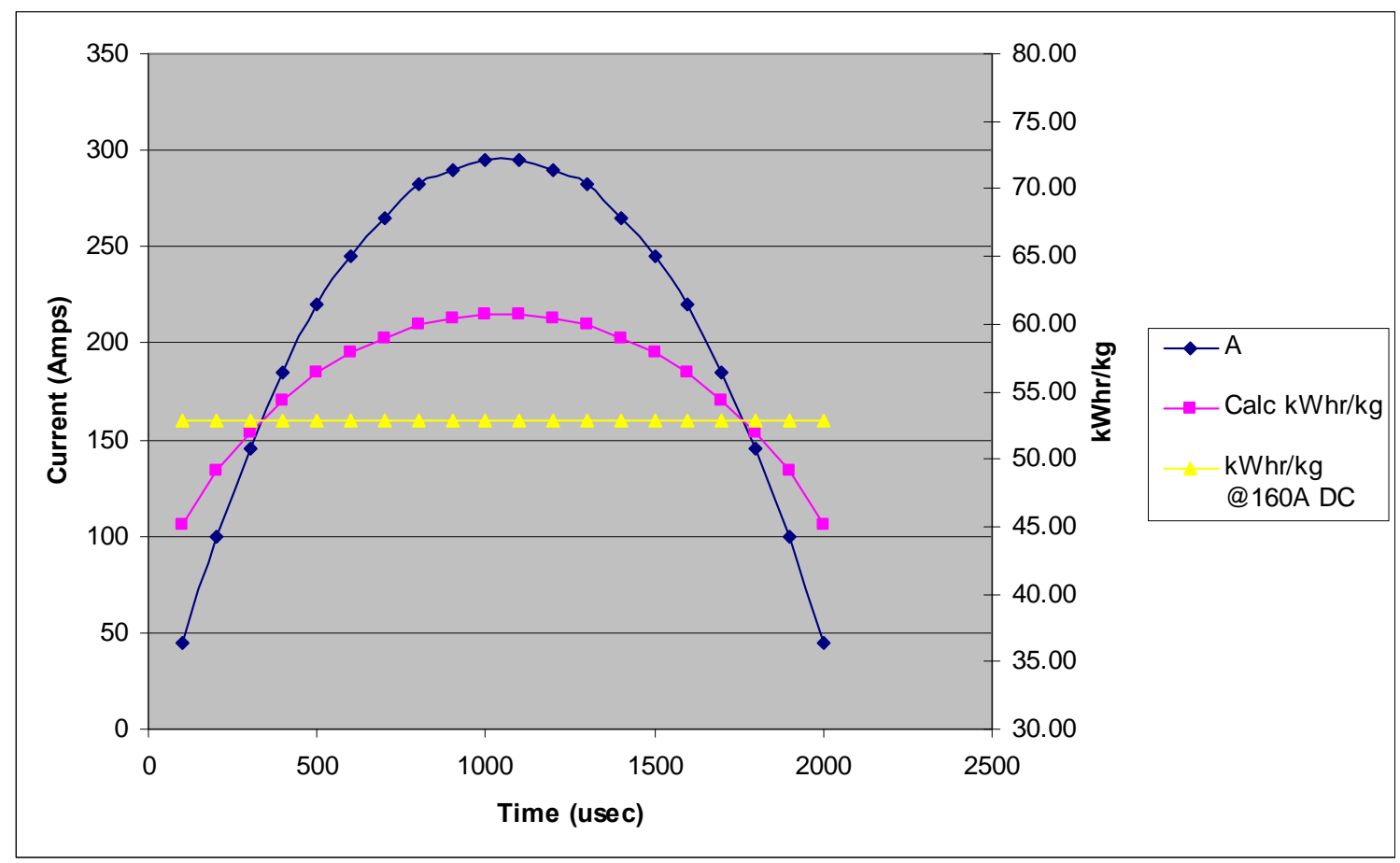

\section{Figure 3.2-3: Calculated Hydrogen Production Efficiency During One Current Pulse}

While the IGBT alternative was not tested, the available information shows that there are significant advantages with it. The 300kW IGBT supply considered in the trade study was a two-stage converter and had an electrical efficiency of approximately 95\%. While lower than the SCR-based supply, the IGBT supply provides steady DC current to the cell stack, and thus does not suffer the $6 \%$ penalty for pulsed current.

One additional consideration is that IGBT is the prevalent technology being used for converting wind turbine output power to grid compatible voltages and frequencies. With the strong growth in the global wind turbine industry, it is likely that IGBTs will go through rapid development to lower costs and improve reliability and performance. There are other commercial applications requiring large DC current for operation such as electroplating or mining. The power systems have traditionally utilized SCR devices. IGBT devices are being incorporated since they result in smaller, lower cost systems due the ability to switch at higher frequencies. As electrolysis systems grow, they will be able to capitalize on these commercially available IGBT based power systems.

\subsection{Cell Stack}

The technical decision of cell architecture (current production design vs. bipolar plate design) leans towards bipolar plate design for reduced part count and the ability to benefit from developments in fuel cell bipolar plate technology. Additional cost analysis will be necessary to make a final decision. 


\section{Hydrogen Generation From Electrolysis}

The cell stack electrical configuration, series or parallel, depends on the choice of power supply. In general, the closer the DC buss voltage is to the rectified input AC voltage the more efficient the power supply is. By connecting the stacks in series, the DC buss voltage of the power supply could be raised to about 500 to $700 \mathrm{~V}$, depending on the number of cells. This enabled the expansion of choices to high power SCR and IGBT supplies used in industrial and chemical processing applications. The selection of IGBT as the primary candidate by default chooses a series configuration for the stacks. The fluid connections are in parallel.

There is significant progress towards the DOE targets. By changing the cell stack parameters shown in Table 3.3-1, the efficiency was raised from $48 \%$ to $58 \%$ based on LHV.

Table 3.3-1: Factors Contributing to Efficiency Improvement

\begin{tabular}{|l|c|c|}
\hline & $\begin{array}{c}\text { Current Production } \\
12 \mathrm{~kg} / \text { day }\end{array}$ & $\begin{array}{c}100 \mathrm{~kg} / \mathrm{day} \\
\text { System }\end{array}$ \\
\hline Stack Operating Temperature $\left({ }^{\circ} \mathrm{C}\right)$ & 50 & 80 \\
\hline Current Density $\left(\mathrm{A} / \mathrm{cm}^{2}\right)$ & 1.9 & 1.65 \\
\hline Membrane thickness (mil) & 10 & 7 \\
\hline Anode exchange current density (normalized) & 1 & 3 \\
\hline Hydration estimate (normalized) & 1 & 1.18 \\
\hline
\end{tabular}

These factors contribute roughly $7 \%$ of the efficiency improvement. Other effects not directly related to the cell stack also improve the efficiency.

- Auxiliary loads are a smaller percentage of the total, due to larger scale

- Improved dryer efficiency, by virtue of higher swing pressure with lower moisture loading, results in less hydrogen vented to regenerate, netting a higher $\mathrm{H} 2$ yield

- Improved power supply efficiency

In order to reach the 2012 target of 69\% efficiency (LHV), the following changes are anticipated to make significant contributions:

- Larger size Bi-polar plate architecture cell stacks

- 5 mil membrane for lower cell voltage operation

- Operation at lower current density as capital cost improvements are realized

- Continued improvement in catalyst performance 


\section{Hydrogen Generation From Electrolysis}

\subsection{Hydrogen Separation}

Hydrogen is generated on the opposite side of the membrane from the water input, but significant amounts of water cross the membrane along with the protons. In general, for every proton that crosses the membrane, nine molecules of water are pulled across. For $100 \mathrm{kgH}_{2} /$ day size systems, this water flow is about $5.5 \mathrm{~kg} / \mathrm{min}$ of water. At the separator input, the gas is about $80 \%$ by volume, depending on a variety of factors.

The water removed in the separator is returned to the water loop so there must be a mechanism to prevent hydrogen from using the same pathway and entering the water storage tank. The typical method is to use level control to keep a minimum level of water in the separator, and pull the water from the bottom of the separator.

Another design consideration is that the level of water can get too high and the excess water will be carried with the hydrogen into the dryers, severely reducing the desiccant life and effectiveness.

After the initial trade study was completed, a method for sizing separators was found, using the Souders-Brown equation. The equation establishes the maximum vertical gas velocity that will not entrain liquid droplets, based on the density of the gas and the liquid. The analysis showed that a diameter of 1.25 ” with the estimated gas flow would keep the velocity below the predicted limit.

In order to validate the analysis, tests were performed on a few configurations of a very simple separator using low-pressure air as a substitute for high-pressure hydrogen. The conditions were set so that the actual volumetric flow rate and density of the air duplicated that of the hydrogen at operating conditions. The water flow rates duplicated the predicted production flow rates. The simplest design was evaluated to get an idea of the flows involved, and how much additional complexity might be needed to get the desired performance.

The results showed that a 3" diameter tee was sufficient to separate the flows. Some splashing caused droplets to be carried up to the exit tube, but adding a layer of steel wool captured the splashes. A smaller diameter may be sufficient, especially in the upper half, if there are baffles or demisters added to eliminate splashes. A smaller diameter in the lower half would reduce the holdup volume, and increase the entrainment of gas bubbles in the water due to the high turbulence in the flow. Again, baffles to slow the water flow will help reduce that problem, but in the short term, the 3" diameter pipe was effective.

\subsection{Oxygen Separation}

As mentioned above, oxygen is generated inside the cell stack on the same side of the membrane that the feed/cooling water is flowing. The oxygen must be separated from the water before the water is returned to the cell stack. At the separator, the gas is about $50 \%$ by volume, depending on the pressure in the separator and the quantity of water needed for cooling. Assuming a worst-case cell voltage of $2.5 \mathrm{~V}$, the amount of heat to be removed is about $120 \mathrm{~kW}$. If we assume a $10^{\circ} \mathrm{C}$ rise in water temperature, the flow rate must be about $175 \mathrm{~kg} / \mathrm{min}$. The standard $100 \mathrm{kgH} 2 /$ day system will vent the oxygen to atmosphere, but there will be an option to provide oxygen at 1.5 barg for other uses. 


\section{Hydrogen Generation From Electrolysis}

In order to size the separator and tank, a full-scale mockup was assembled, Figure 3.5-1: Full Scale Oxygen Separator Mock-up. It was operated with 45 gpm of water and 16 SCFM of air. A 6" diameter tee was used, similar to the hydrogen separation tests. Even with a 2' long lower branch, the entrainment of air into the water was a problem. Possible solutions would include baffles to reduce the velocity of the water or to create a cyclonic flow. Another approach would be to have a separator for each individual cell stack so the flows would be smaller.

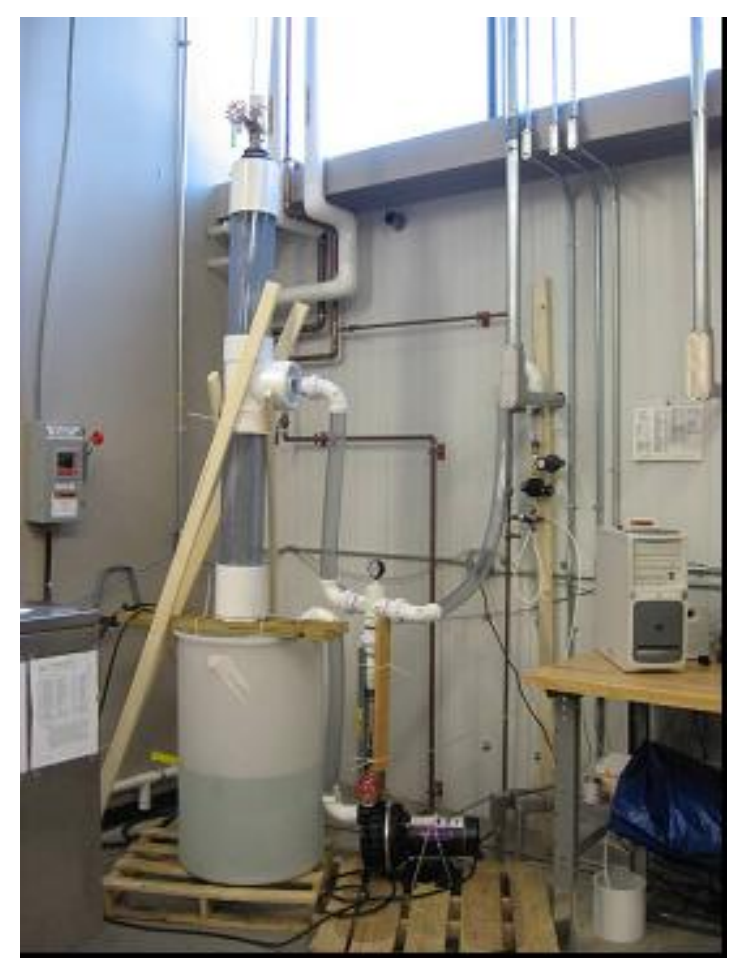

Figure 3.5-1: Full Scale Oxygen Separator Mock-up

\subsection{Hydrogen Dryer}

The trade study examined a variety of concepts; from the PSA (Pressure Swing Adsorption) dryer used in our current products to a membrane dryer and a large scale commercial PSA. In addition, pre-condensers to bring the dew point down below proposed system operating temperature of $80^{\circ} \mathrm{C}$ were considered, and the tradeoff of different temperatures was evaluated. The options for the pre-condensing technology included Thermal Electric Coolers (TEC) and chillers. The result of the study recommendation was to use a chiller and heat exchanger before the dryer to get the hydrogen to $15^{\circ} \mathrm{C}$, then use a PSA dryer similar to today's system. The chiller implementation is cost effective, commercially available, and electrically efficient in the size range needed. The size of the dryer would not change significantly, except the column diameter would need to expand slightly to handle the larger throughput. 


\section{Hydrogen Generation From Electrolysis}

\subsection{System Output Pressure}

One of the requirements for fueling systems is to provide hydrogen at a high pressure for compact storage, typically 350 bar (5076 psi) or 700 bar (10,152 psi) depending on the vehicle manufacturer. There is a tradeoff between higher electrolyzer output pressure and higher compression ratio in the compressor.

Several commercially available compressor types were evaluated, and the overall system cost savings over 5 years for electrolyzer output pressure ranging from 400 psi to 800 psi varies significantly. One type examined shows that increasing the electrolyzer output pressure to 55 bar (800 psi) will drop the compressor cost by $\$ 16 \mathrm{~K}$, and the power input cost by $\$ 5 \mathrm{~K} / \mathrm{yr}$. Best estimates from all the data indicates that if a high-pressure cell stack adds more than $10-20 \%$ to the cost, it will overcome savings from a compressor with a higher suction pressure.

On the low-pressure end, some minimum pressure, perhaps 1.5 bar (22 psi), would be necessary to ensure that in case of a leak the oxygen does not diffuse into the hydrogen side. The question is whether a low pressure stack would reduce total stack costs and balance of plant costs to make up for the additional compressor costs. Low-pressure cell stack and balance of plant costs would need to be reduced by $15 \%$ to make up for the higher compressor costs over 5 years. 


\section{Hydrogen Generation From Electrolysis}

\section{Conceptual Design Summary}

The purpose of the conceptual design is to take the results of the trade studies and translate them into specific, if preliminary, hardware specifications, configurations and costs. This served as the basis for refining the capital and maintenance costs used to perform the H2A analysis. Costs estimates and quotations for the subsystems are based on 100 units per year, after 2 years of lower volume production.

\subsection{Electrolyzer System}

The process for conceptually designing the $100 \mathrm{~kg} \mathrm{H2/day} \mathrm{system} \mathrm{packaging} \mathrm{began} \mathrm{with}$ a preliminary parts list of the major components with their approximate sizes. Some of these components were similar to parts currently being used on existing Proton products, such as the pump and heaters. Other components were modified parts, such as a hydrogen drier with larger desiccant tubes. Still other components were rough rectangular forms of the space required to mount it, such as heat exchangers and a new oxygen/water separator.

The next step was to brainstorm multiple configurations for housing the $100 \mathrm{~kg} \mathrm{H} 2 /$ day system components. The starting point for the concepts included having an oxygen/water compartment and separate hydrogen and electrical compartments. Variations included splitting the electrical bays into separate power and control cabinets to minimize the arcflash hazard in the control area. There were several variations in the arrangement of the cabinets ranging from all in a row, to back to back versions, some with doors on two or three sides, and still another where some cabinets were accessed from inside a steel skid structure. All these variations tried to abide by several design considerations created by the team as listed below:

- Short reach-in depth for working on components

- Separate electrical bays (E-Bay Power and E-Bay Control) to minimize the arcflash hazard in the control cabinet

- Separate Hydrogen and Oxygen compartments (H -Bay and O-Bay) to minimize the risk of hydrogen combustion and simplify ventilation strategies.

- Ship in one piece to minimize field assembly time (turn-key)

- Ship cell stacks separately to minimize weight and risk of freezing

- Fork lift access for Cell Stacks and Power Supply due to weight

- Minimize enclosure sides with connections and door to allow mounting against walls for ease of siting

- Arrange power supply and cell stacks to minimize cabling and material for high power transmission

- Even weight distribution for better shipping and handling

- Good ratio of length to width for strength, ease of siting, and shipping

- Outdoor installation considerations, weather and temperature

- Minimize enclosure size for ease of shipping, handling, siting, installation (Sized to fit inside standard ISO containers)

- Minimize heating, cooling, and ventilation requirements.

- Make easy access to service items to reduce cost of repairs 


\section{Hydrogen Generation From Electrolysis}

All nine enclosure concepts were measured against these design considerations. One design, pictured below in Figures 4.1-1 and 4.1-2, best met the considerations in a wellbalanced manner.

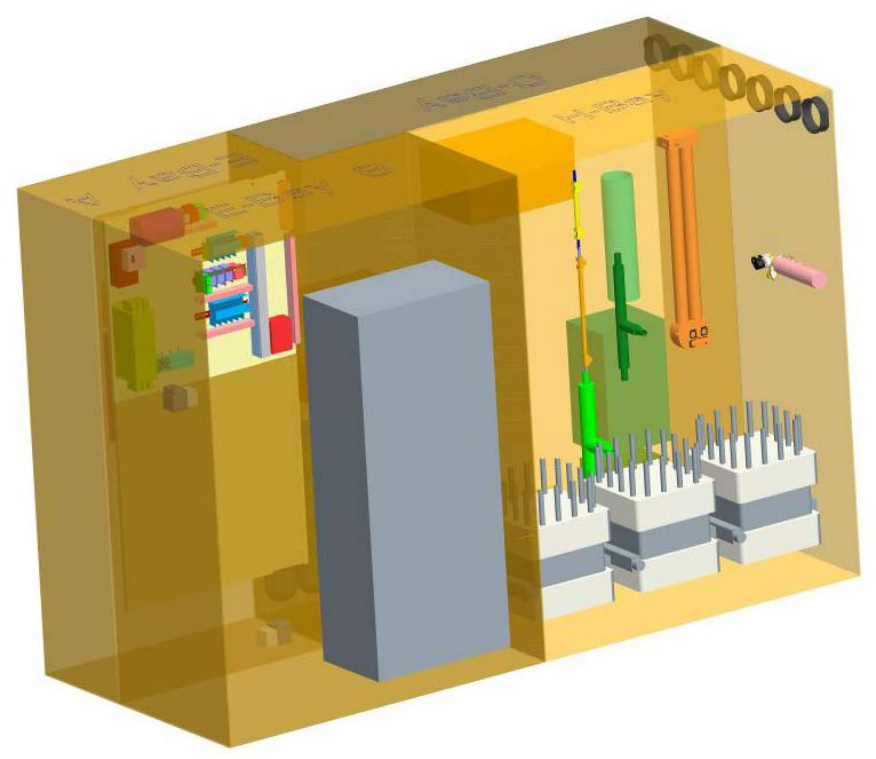

Figure 4.1-1: Front View, Showing Power Bay on the Left and H2-Bay on the Right

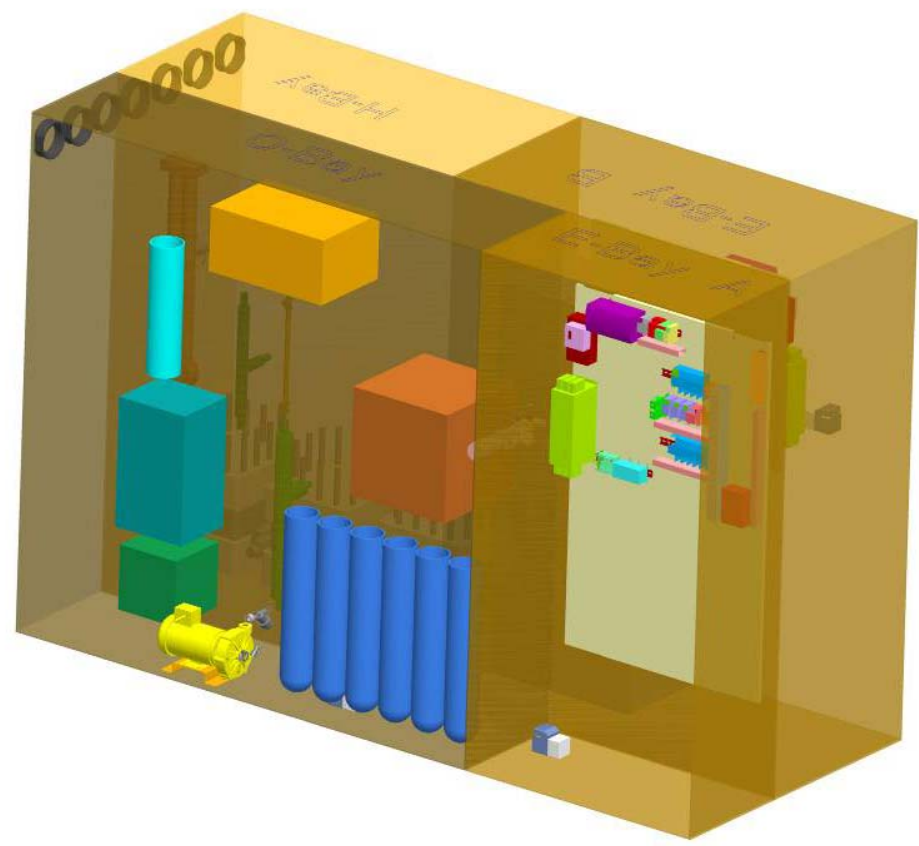

Figure 4.1-2: Rear View, Showing O2/Water-Bay on the Left and Controls Bay on the Right

The unit size is approximately $1.5 \mathrm{~m} \mathrm{D} \times 3.5 \mathrm{~m} \mathrm{~W} \times 2 \mathrm{~m} H$ with access on two opposite sides. There are separate hydrogen and oxygen compartments, and separate control and 


\section{Hydrogen Generation From Electrolysis}

power electronics compartments. The control and oxygen compartments are $0.6 \mathrm{~m}$ deep to minimize the reach-in depth, while the hydrogen and power electronics bays are $0.9 \mathrm{~m}$ deep to accommodate the power supplies and cell stacks. These hydrogen and power electronics bays are also adjoining on the same side to minimize the length of electrical connections and consolidate all items that need a fork lift to install on one side. One drawback of this design is that only one of the shorter sides is without access panels or connections.

This design is a starting point to refine the arrangement towards a producible product. Future work will be required to determine the optimal wiring and plumbing paths, creating leak free wall penetrations for buss bars if needed, and giving more definition to the many rough component models. Lastly, the structure itself needs more attention to determine the best way to acquire or build the compartments. The possibilities include purchasing one large welded skid structure or bolting together four smaller cabinets. As the components become more detailed and construction and assembly techniques are given more scrutiny, this design can adapt to changes in overall size, individual compartment size and varying number, size, and placement of access panels and doors. All these efforts will result in a product that meets customers' requirements but is also easy to produce, site, and service.

\subsection{System Cooler}

A simple air-cooled heat transfer design was chosen over evaporative or refrigerated systems due to lowest power consumption, highest reliability, small footprint and least environmental impact. The air-cooler will use 50\% propylene glycol/water mix as a media coolant with the heat exchangers. The requirement for the cooling system is a total load of about $135 \mathrm{~kW}$. The coolant is routed through the system into heat exchangers specific to the cell stacks, guard bed, power supply, and dryer. Elevating the system operating temperature to $80^{\circ} \mathrm{C}$ provides sufficient temperature gradient to enable efficient direct heat transfer even in warm climates; possible cogeneration opportunities were not evaluated but could lead to further operating energy economies.

In working with two potential suppliers, the footprint of the cooler can be between $1.2 \mathrm{~m}$ $\mathrm{x} 2.4 \mathrm{~m}$ to $1.2 \mathrm{~m}$ x $4.8 \mathrm{~m}$ depending on the configuration. The simplest design of a single coil, four in-line fans, pump, reservoir tank and controls has the largest footprint and is subject to other additional cooling methods, such as evaporative mist-assist or controls to ensure adequate cooling in high-temperature climates $\left(>40^{\circ} \mathrm{C}\right)$. The smaller footprint is a more complex design involving a dual cooling loop ( 2 pumps, 2 coils, 2 tanks, 2 inline fans), but can be designed to more easily meet the higher temperature climates. Budgetary quotes for both types of systems were obtained. Because these cooling systems can be relatively easily custom-designed to meet different operating environments, the approach may be to approve a family of coolers that are matched to a given geographical region. 


\section{Hydrogen Generation From Electrolysis}

\subsection{Preliminary Hazard Analysis Summary}

A Preliminary Hazard Analysis (PHA) was performed to examine the proposed system for hazards and determine mitigation techniques and safeguards. Safeguards and other hazard mitigation techniques can have an effect on items such as enclosure construction so inclusion of the costs is necessary for high fidelity estimates.

A modified version of the risk matrix from SEMI S10-1296, Safety Guideline For Risk Assessment, was used for the analysis. The same severity and likelihood levels were utilized, but the likelihood and risk rankings were converted to numbers for ease of use with the software tool utilized. This risk matrix was selected because of its familiarity to the Proton engineering team and its successful use in the semiconductor industry that often must address the hazards of flammable and even toxic gases as well as many types of machinery hazards.

The hydrogen generation system was divided into the following four systems for the analysis:

- Hydrogen compartment

- Water / Oxygen compartment

- Electrical compartment

- Cooler

These systems were then divided into lower level subsystems as required to facilitate the analysis.

The hydrogen compartment was analyzed first as it is where the most elements of the system come together, and is therefore the place where the most hazards are likely to exist. The standard checklist of potential hazards found in EN 1050, Safety Of Machinery, Principles For Risk Assessment, was reviewed against the design and operation of the cell stack subsystem. This process was repeated for all the subsystems using references to, or information from, the cell stack subsystem as much as possible to reduce the amount of redundant analysis.

During the PHA, it became apparent that hazard consequences and severity, likelihood to occur, and risk rankings could vary considerably between operations, e.g. installation, hydrogen generation, maintenance, service, etc. Another column was added to the PHA worksheet to capture this and to indicate more clearly, which safeguards addressed which operations and what personnel.

Several main themes became apparent during the performance of the PHA:

- Separating the controls, supervisor circuits, and communications from the electrical power distribution and cell stack power supply section(s) would allow maintenance and/or service personnel to perform many of their tasks without exposure to potential Arc Flash / Arc Blast hazards.

- Using a "floating” (ungrounded output) cell stack power supply operating at hazard voltages will require an approach to electrical safety not used in current production electrolyzers (but not uncommon in other types of equipment). 


\section{Hydrogen Generation From Electrolysis}

- The cooler was responsible for a surprising number of recommendations and especially high priority recommendations. Better definition of the cooler will likely allow the elimination of, or a reduction in priority for, many of the recommendations as the cooler is a relatively simple subsystem compared to the rest of the system. Integrating the cooler into the other subsystems could also eliminate many of the other recommendations.

- Using Extra Low Voltage (ELV) electrical equipment (approximately < 42 volts) and using NRTL / NB (Nationally Recognized Testing Laboratory/Notified Body) approved components installed per NFPA 70 and NFPA 79 wherever possible will address most of the arc flash / arc blast and electrocution hazards.

- Building in a hoist for lifting heavy components like cell stacks should be considered.

- Guarding can address many of the mechanical hazards like cutting from fans, entanglement in pump motor shafts, hot surfaces of components or piping, and spraying liquids.

These high-level recommendations can be included into the next level of design effort for electrolyzer systems in the $100 \mathrm{~kg} /$ day size range in a cost effective manner. The different design alternatives for achieving the desired risk mitigation are traded early on in the design process for inclusion. 


\section{Hydrogen Generation From Electrolysis}

\section{Cell Stack Cost Reduction Study}

\subsection{Background}

The electrolyzer cell stack is currently one of the most expensive sub-components of the hydrogen generating system. Expensive materials and manufacturing processes are employed in the manufacture of the stack in order to meet efficiency and reliability requirements. Typically, in commercial electrolyzers the cost of the membrane electrode assembly (MEA) is between $20 \%$ and $40 \%$ of the cost of the cell stack. This makes the MEA the single most expensive component in the cell stack.

The goal of this project was to identify cost reduction opportunities of the cell stack by optimizing the materials used in the fabrication of the MEA. Specifically evaluated were catalyst and membrane materials that have performance and cost advantages over those currently used. In addition, the impact of operating conditions, specifically temperature, on the efficiency of the MEA was explored.

\subsection{Approach}

The following topics were identified as potential cost reduction activities, and were evaluated in this study:

- Evaluation of Efficiency Gains Through High Temperature Operation

- Optimization of Catalyst Loading for Performance \& Cost

- Evaluation of Lower Cost / Higher Performance Catalysts

- Evaluation of Lower Cost / Higher Performance Ion Exchange Membranes

Breaking the project down into the topics shown above enabled the evaluation of each cost reduction effort independently. This allowed a more fundamental understanding of the impact each change had on the operating efficiency and cost of the electrolyzer cell stack. Whenever a new material / process was used in the MEA fabrication process, the manufacturability as well as the physical properties of the MEA were recorded.

The first three topics were evaluated using 3-cell, $86 \mathrm{~cm}^{2}$ electrolyzer cells stacks. The stacks were run on internally developed proprietary R\&D test stands at the following conditions:

$\begin{array}{ll}\text { Operating Temperature: } & 50^{\circ} \mathrm{C} \\ \text { Operating Current Density: } & 1850 \mathrm{~mA} / \mathrm{cm}^{2} \\ \text { Hydrogen Pressure: } & 200 \mathrm{psig} \\ \text { Oxygen Pressure: } & 10 \mathrm{psig}\end{array}$

The test stands allow accurate control of the operating temperature of the cell stack, thereby removing the inaccuracies associated with voltage / temperature corrections. Automated data acquisition logged relevant information including inlet/outlet temperature, pressure, current, and voltage at ten second intervals. The test stands also ran automated voltage / current polarization curves at predefined time intervals. A baseline cell was included in each test stack to monitor any process / hardware variations 


\section{Hydrogen Generation From Electrolysis}

that could affect the test results. Long-term performance data was generated by running the stacks for 1,000 hours at the operating conditions shown above. Previous testing has shown that cells remain very stable after this point, making it possible to accurately predict future performance.

The fourth topic, "Evaluation of Lower Cost / Higher Performance Ion Exchange Membranes," was evaluated using a 20-cell electrolyzer of the same cell configuration previously mentioned. Testing on the 20-cell level provided more statistical cell data as well as the opportunity to evaluate the stack performance in a commercial Hogen ${ }^{\mathrm{TM}} 40$ system. This test reproduced the operating conditions that a stack would experience at a customer site.

\subsection{Efficiency Gains Through High Temperature Operation}

Proton's commercial hydrogen generator products typically operate up to about $50^{\circ} \mathrm{C}$. Balance-of-plant simplicity as well as material compatibility issues have defined this operating range. However, it is well known that increasing the operating temperature of the cell stack will decrease the over-voltage of the electrolysis reaction resulting in increased efficiency. This voltage efficiency gain can be offset by a loss in current efficiency due to increased hydrogen crossover. A study was undertaken to determine the effect of operating temperature on electrolyzer performance.

\section{Experimental Setup}

The temperature efficiency experiment was run with Proton's standard 3-cell electrolyzer test hardware cell configuration. The cell stack was tested on Proton's in-house proprietary R\&D test stand per standard internal testing protocols. Slight modifications of the test stand were made in order to enable high temperature operation to the conditions outlined below. The operating conditions were as follows:

$\begin{array}{ll}\text { Operating Temperature: } & 18 \text { to } 80^{\circ} \mathrm{C} \\ \text { Operating Current Density: } & 0 \text { to } 2150 \mathrm{~mA} / \mathrm{cm}^{2} \\ \text { Hydrogen Pressure: } & 0 \text { to } 200 \mathrm{psig} \\ \text { Oxygen Pressure: } & 10 \text { psig }\end{array}$

Automated data acquisition logged relevant information including inlet/outlet temperature, pressure, current, voltage, etc. Current-voltage polarization curves were run at temperatures of $18^{\circ} \mathrm{C}, 50^{\circ} \mathrm{C}$ and $80^{\circ} \mathrm{C}$ at $\mathrm{H} 2$ generation pressures of 0 psi and $200 \mathrm{psi}$. The temperature of the cell stack was controlled using a commercially available heater/chiller that monitored the temperature of the cooling water exiting the stack. The stack was allowed to reach steady state at each temperature and pressure before beginning a polarization curve. Voltage data collected from the three cells were averaged in order to reduce any cell-to-cell variability.

\section{$\underline{\text { Results }}$}

Polarization data collected at various temperature ranges were compiled and converted to electrolyzer efficiency versus current density. Measured cell voltages were converted to voltage efficiency using the following equation: 


\section{Hydrogen Generation From Electrolysis}

$$
\text { Eff }_{\text {VOLTAGE }}=1.23 \div \mathrm{E}_{\text {CELL }}
$$

where $\mathrm{E}_{\mathrm{CELL}}$ represents the average cell potential at a particular set of conditions. Current

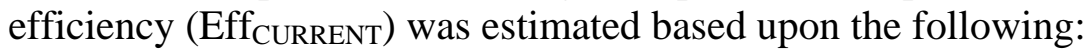

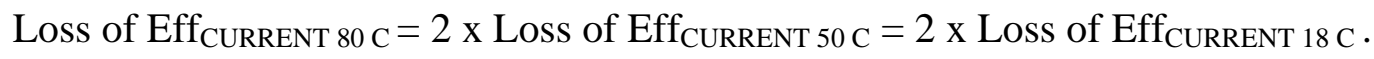

Total efficiency of the electrolyzer was calculated as the product of the voltage and current efficiencies:

$$
\mathrm{Eff}_{\text {TOTAL }}=\text { Eff }_{\text {VOLTAGE }} \mathrm{x} \text { Eff }_{\text {CURRENT }} .
$$

Results are presented in Figure 5.3-1 for three temperatures: 18, 50 and $80^{\circ} \mathrm{C}$. DOE targets for electrolyzer stack efficiency are included for comparison. It should be noted that the targets are from the 2004 period when the work was performed. The effect of temperature on efficiency can be observed at the very low range of current density. There is a crossover in efficiency that occurs between 18 and $80^{\circ} \mathrm{C}$ due to increase in hydrogen crossover. The effect is small because the operating pressure is only $200 \mathrm{psig}$. At higher differential pressures, this efficiency loss can be quite large at the low current densities.

Temperature has a significant effect on electrolyzer efficiency. Efficiencies as high as $70 \%$ can be achieved with an increase in operating temperature while maintaining reasonably high current densities. This is important in order to keep the capital cost of the cell stack to a minimum, as the size of the cell stack is inversely related to operating current density.

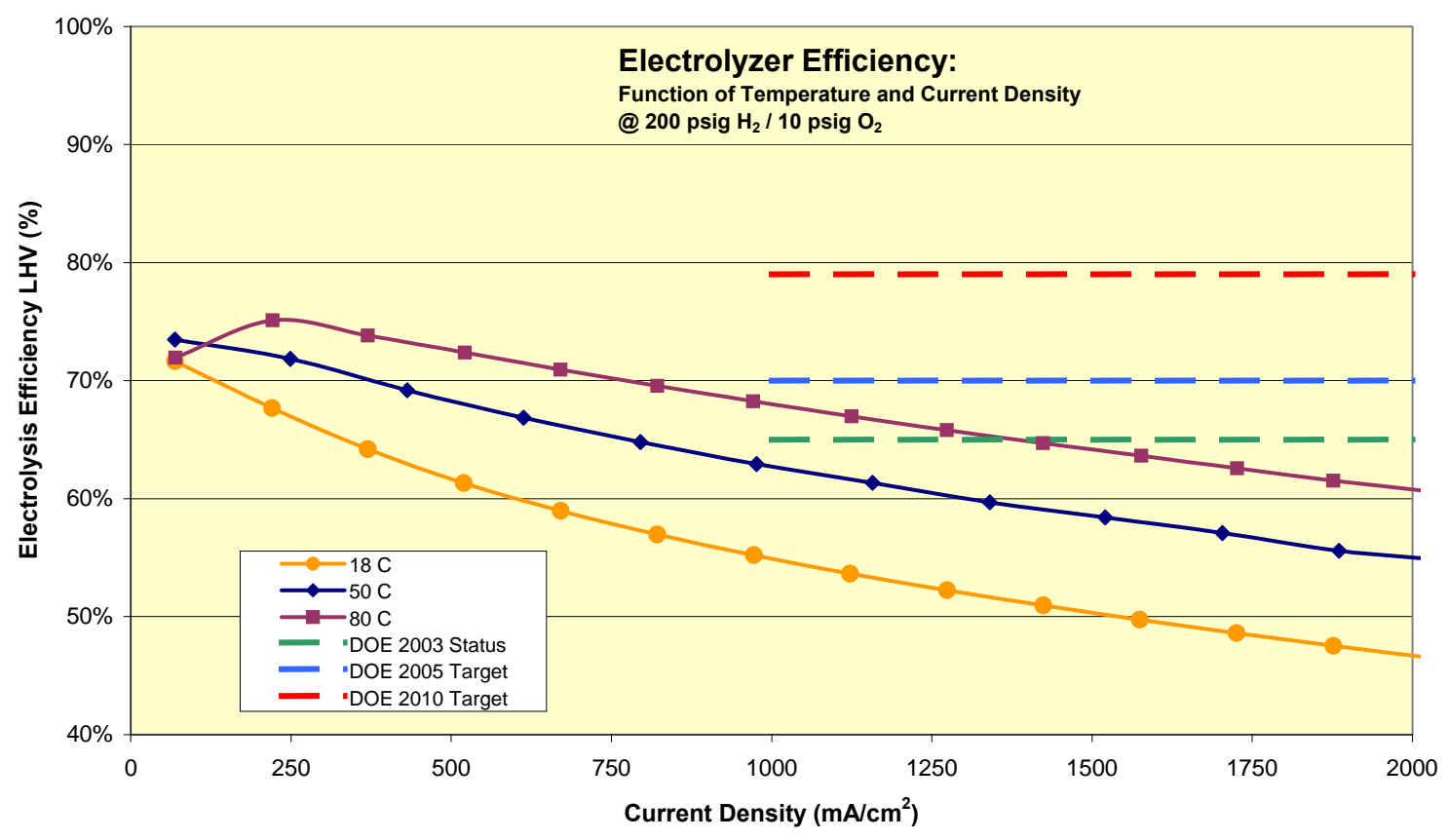

Figure 5.3-1: Efficiency Versus Current Density as a Function of Temperature

Overall, current electrolyzer stack technology can meet the 2003 and 2005 DOE efficiency targets over a reasonable range of current densities. Increasing the stack 


\section{Hydrogen Generation From Electrolysis}

operating temperature may allow the electrolyzer to meet the 2010 DOE targets for electrolyzer efficiency at operating current densities that are economically viable, especially with other performance improvements outlined elsewhere in this report.

\subsection{Optimization of Catalyst Loading for Performance and Cost}

The precious metals used to facilitate the oxidation and reduction reactions in PEM electrolysis represent a significant portion of the total stack cost. Because the catalyst is expensive, there is always a drive to reduce the catalyst loading on the surface of the MEA. One of the challenges of reducing catalyst loading is maintaining a uniform catalyst distribution on the surface of the MEA. Non-uniform catalyst distribution invariably decreases electrochemical efficiency, which translates into a reduction in the amount of gas that can be generated for a given power input to the cell. In order to compensate for the reduction in output, it is necessary either to increase the number of cells in the stack or to increase the power input to the stack. These changes would increase the capital cost and/or operating cost of the cell stack thereby negating any savings realized by reducing the catalyst loading. For this reason, it is important to optimize catalyst loading for both electrochemical efficiency as well as cost. The goal of this project was to evaluate the impact that reduced catalyst loading has on the cost, manufacturability and electrochemical performance of the membrane electrode assembly.

\section{Experimental Setup}

The reduced catalyst loading MEA configurations evaluated under this task are summarized in Table 5.4-1 below.

Table 5.4-1: Reduced Catalyst Loading MEAs Evaluated

\begin{tabular}{|c|c|c|c|}
\hline MEA Type & $\begin{array}{c}\text { Reduction in Anode } \\
\text { Catalyst Loading }\end{array}$ & $\begin{array}{c}\text { Reduction in Cathode } \\
\text { Catalyst Loading }\end{array}$ & $\begin{array}{c}\text { Total Reduction in } \\
\text { Catalyst Cost }\end{array}$ \\
\hline Baseline & None & None & None \\
\hline A & $33 \%$ & $25 \%$ & $30 \%$ \\
\hline B & $66 \%$ & $50 \%$ & $60 \%$ \\
\hline
\end{tabular}

The evaluation of the reduced catalyst loading MEAs included the following:

1. Electrode fabrication process

2. Lateral conductivity of each catalyst layer

3. Cross-cell resistance of the MEA

4. Electrochemical performance

Four MEA samples of each catalyst-loading configuration were evaluated for manufacturability, lateral conductivity and cross-MEA resistance. The samples were made using standard MEA fabrication process and using similar lots of membrane and catalyst material. Visual examination of the MEAs during key processing steps was compared to the baseline. Of particular interest was the overall uniformity of the catalyst layers, the thickness of the catalyst layers and the presence of any voids. 


\section{Hydrogen Generation From Electrolysis}

The lateral conductivity of each catalyst layer was measured using an internally developed proprietary measurement device in combination with an AC signal. Three measurements were made for each catalyst electrode and then averaged. The cross-MEA resistance measurements were also made using a separate internally developed measurement device, again with an AC signal. The conductivity results are specific to the measurement devices used, and therefore only useful for comparison purposes.

The electrochemical performance of each reduced catalyst loading MEA configuration was evaluated in a standard Proton 3-cell electrolyzer test stack. One stack was built with two MEAs containing catalyst reduction A, whereas a second stack was used to evaluate two MEAs made with catalyst configuration B. A baseline MEA made with nominal catalyst loadings was also included in each stack. The voltage data for each MEA configuration was averaged in order to minimize the significance of any cell-to-cell performance variations.

The stacks were run on Proton's R\&D test rigs at the following operating conditions:

$\begin{array}{ll}\text { Operating Temperature: } & 50^{\circ} \mathrm{C} \\ \text { Operating Current Density: } & 1850 \mathrm{~mA} / \mathrm{cm}^{2} \\ \text { Hydrogen Pressure: } & 200 \mathrm{psig} \\ \text { Oxygen Pressure: } & 10 \mathrm{psig}\end{array}$

Automated polarization curves were run after 24 hours operation and then after every 100 hours of operation over the duration of the test. During polarization curves, current was swept from 65 to $2150 \mathrm{~mA} / \mathrm{cm}^{2}$ in increments of $140 \mathrm{~mA} / \mathrm{cm}^{2}$. Each current increment was held at steady state for several minutes before voltage measurements were recorded.

\section{Results}

There was no visible difference in the catalyst uniformity of the MEAs made with reduced catalyst loading A compared to that of the baseline. The reduction in catalyst loading had no impact on current electrode fabrication process. The MEAs made with reduced catalyst loading $B$, however, showed a marked decrease in catalyst uniformity over that of the baseline MEAs. The catalyst layers were thin and wispy, leaving large areas of the membrane exposed. This non-uniformity resulted in significantly higher lateral catalyst resistance as is shown in Table 5.4-2.

Table 5.4-2: Normalized Cross-Cell and Lateral MEA Resistance

\begin{tabular}{|c|c|c|c|}
\hline $\begin{array}{c}\text { Catalyst } \\
\text { Loading }\end{array}$ & $\begin{array}{c}\text { Relative Anode Catalyst } \\
\text { Resistance }(\mathbf{m O h m})\end{array}$ & $\begin{array}{c}\text { Relative Cathode Catalyst } \\
\text { Resistance }(\mathbf{m O h m})\end{array}$ & $\begin{array}{c}\text { Relative Cross-Cell MEA } \\
\text { Resistance (mOhm) }\end{array}$ \\
\hline Baseline & 1.0 & 1.0 & 1.0 \\
\hline A & 1.4 & 0.7 & 1.0 \\
\hline B & 16.2 & 2.3 & 1.0 \\
\hline
\end{tabular}




\section{Hydrogen Generation From Electrolysis}

The lateral resistance of catalyst loading A was close to that of the baseline, which supports the visual observations of catalyst uniformity. The cross-cell MEA resistance is a measurement of the membrane conductivity and was therefore unaffected by the reduction in catalyst loading. Figure 5.4-1 shows the electrochemical performance of catalyst loading formulations A and B compared to that of the baseline after 24 hours of continuous operation at $1850 \mathrm{~mA} / \mathrm{cm} 2$. In general, there was no significant difference in performance between the three loadings.

Reduced Catalyst Loading Perfomance Comparison

(24 hours, $50^{\circ} \mathrm{C}, 200 \mathrm{psi}_{2}$ )

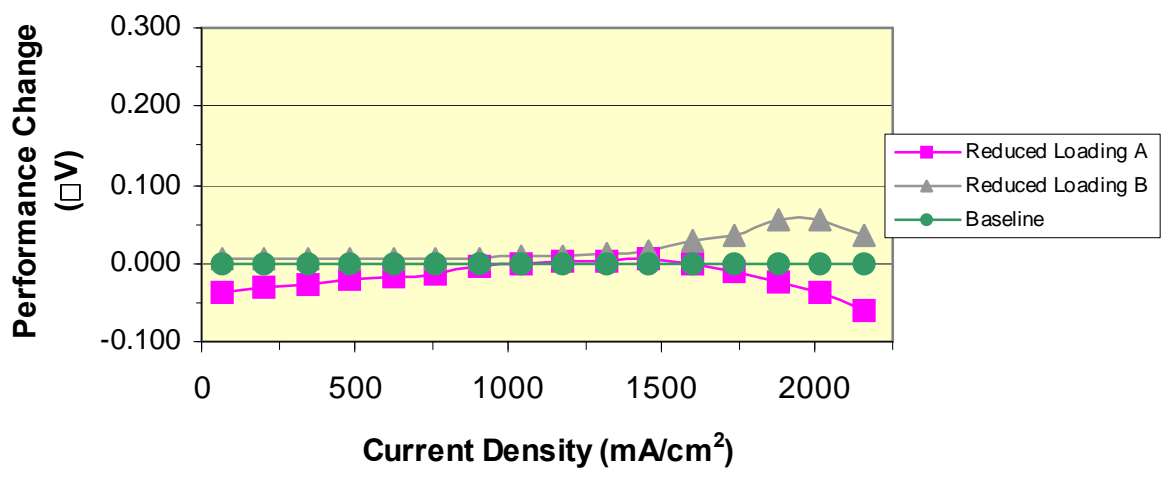

Figure 5.4-1: Catalyst Loading Performance After 24 Hours of Operation

As the cells continued to run, the performance of the MEAs made with reduced catalyst loading A remained fairly close to that of the baseline MEAs. The MEAs made with catalyst loading B did not perform as well, showing a dramatic increase in cell potential after a few hundred hours of operation. This difference in cell potential is illustrated in Figure 5.4-2, which compares the performance of the reduced loading MEAs to that of the baseline after 924 hours of operation.

Reduced Catalyst Loading Perfomance Comparison

(924 hours, $50^{\circ} \mathrm{C}, 200 \mathrm{psi} \mathrm{H}_{2}$ )

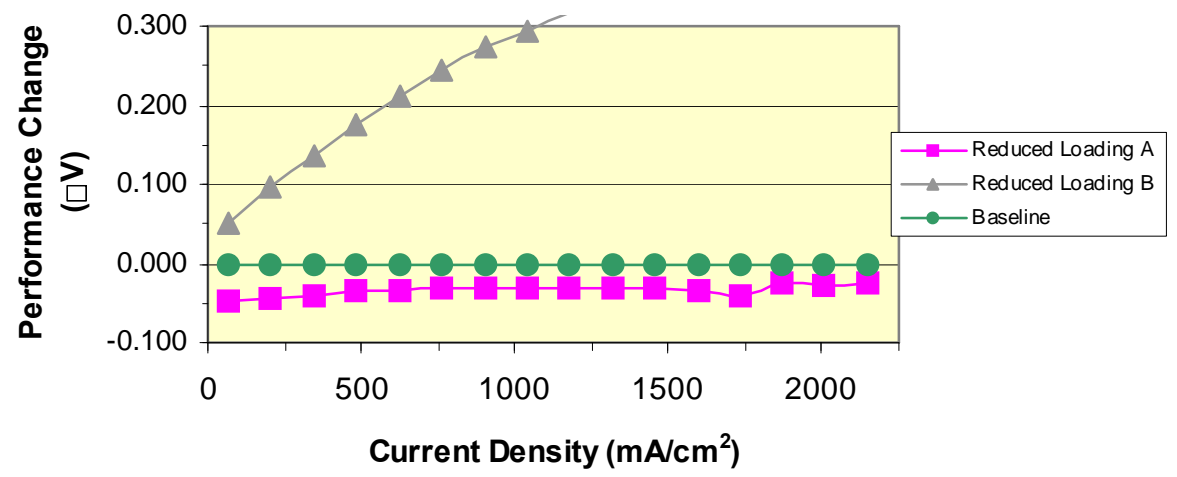

Figure 5.4-2: Catalyst Loading Performance After 924 Hours of Operation 


\section{Hydrogen Generation From Electrolysis}

The slight performance improvement of catalyst loading A over the baseline MEA is not significant given the small sample size being studied.

\section{Conclusions}

This study showed that MEAs made with a 33\% reduction in anode catalyst loading commensurate with a $25 \%$ reduction in cathode catalyst loading performed as well as the corresponding baseline after 1000 hours of operation. In addition, the reduction in loading posed no additional difficulties in manufacturability or in maintaining catalyst uniformity compared to the baseline. This reduction in catalyst loading decreases the total catalyst cost of the MEA by $30 \%$.

The study also showed that reducing the anode catalyst loading by $66 \%$ and the cathode catalyst loading by $50 \%$ dramatically decreased cell performance after several hundred hours of operation. Visual observation and lateral conductivity measurements indicate that the decrease in performance is likely due to non-uniform catalyst distribution on the surface of the MEA. Alternative catalyst application processes will need to be explored in order to maintain catalyst uniformity at these loadings.

\subsection{Evaluation of Lower Cost / Higher Performance Anode Catalyst}

The previous study determined the impact of reducing catalyst loading on the electrochemical performance of the MEA. The catalyst used in that study was made using current manufacturing process, which is expensive and time consuming. The purpose of this study was to evaluate the electrochemical performance of several anode catalysts that offer greater process throughput and cost reduction opportunities over the current catalyst.

\section{Experimental Setup}

Five catalyst samples were identified for this evaluation task. The catalyst samples varied in terms of their synthesis method, chemical composition, and particle size. The samples are summarized in Table 5.5-1.

Table 5.5-1: Oxygen Catalyst Sample Summary

\begin{tabular}{|c|l|c|}
\hline Sample No. & Description & $\begin{array}{c}\text { Specific Surface } \\
\text { Area }\left(\mathrm{m}^{2} / \mathrm{g}\right)\end{array}$ \\
\hline \hline A & Baseline Catalyst & $59-64$ \\
\hline B & Alternate Composition Catalyst & 38.99 \\
\hline C1 & High Activity Alternate Comp & 27.96 \\
\hline C2 & Alternative Process 1 & 39.08 \\
\hline C3 & Alternative Process 2 & 27.86 \\
\hline D & Alternate Comp. 2 (Hydrate) & 39.17 \\
\hline
\end{tabular}

The evaluation process of these catalyst materials consisted of the following:

1. Physical characterization

2. Electrode fabrication process evaluation

3. MEA fabrication process evaluation

4. Electrochemical performance characterization 


\section{Hydrogen Generation From Electrolysis}

Catalyst samples were characterized physically using single-point BET analysis done in triplicate to determine specific surface area. Results of the BET analysis are summarized in Table 5.5-1. Because electrochemistry is dependent on available reactive surface, catalyst surface area is known to have a direct impact on electrochemical activity. After physical characterization, the catalyst samples were fabricated into electrodes, and then MEAs, using proprietary commercial production methods. During this processing, catalysts were evaluated for their ease of handling and "process-ability" compared to the baseline catalyst material. All commercial in-process quality tests were performed. Multiple MEAs were fabricated of each catalyst type and the active area size for all MEAs was $86 \mathrm{~cm}^{2}$. Standard catalyst loadings were used for all oxygen electrodes. For MEA fabrication, Proton's proprietary commercial hydrogen electrode was applied.

For the electrochemical evaluation, the MEAs were assembled into commercial electrolyzer test hardware in a 3-cell configuration. Two cells consisted of the catalyst sample under evaluation and the third cell was designated as a baseline cell. In this way, each test had its own baseline for comparison purposes. The 3-cell stacks were tested using several of Proton's proprietary R\&D test stands and used internal proprietary protocols developed for testing commercial products.

Operating conditions were as follows:

\begin{tabular}{|c|c|}
\hline Operating Temperature: & $50^{\circ} \mathrm{C}$ \\
\hline Operating Current Density: & $1850 \mathrm{~mA} / \mathrm{cm}^{2}$ \\
\hline $\begin{array}{l}\text { Operating Pressure: } \\
\text { Test Duration. }\end{array}$ & $200 \mathrm{psig} \mathrm{H}_{2} / 10$ psig $\mathrm{O}_{2}$ \\
\hline
\end{tabular}

Automated data acquisition logged all relevant stack parameters including temperature, pressure, current, voltage, etc. Current-voltage polarization curves were also conducted automatically at 24 hours after start-up and at regular 100-hr increments thereafter.

\section{$\underline{\text { Results }}$}

All of the catalyst samples were fabricated into MEAs and assembled into 3-cell test articles. Results of the processing evaluations were encouraging. In general, compared to the baseline (Sample A), the other catalyst samples all had a material cost advantage of approximately $30 \%$. In addition, the processing of these catalysts resulted in a reduction in manufacturing labor by approximately $50 \%$.

Samples C1 and C2 were easier to process and resulted in faster throughput during preparation. This translates into a higher manufacturing capacity. In addition, visual inspection of these samples revealed that they looked physically different than the other catalyst samples as well as the hydrogen catalyst. This difference in appearance is desirable, as it would help to reduce operator errors in mixing up the orientation of the MEA.

A graphical summary of the performance testing is presented in Figure 5.5-1. This graph plots the change in cell voltage versus time for the baseline catalyst and each of the five catalyst samples. 


\section{Hydrogen Generation From Electrolysis}

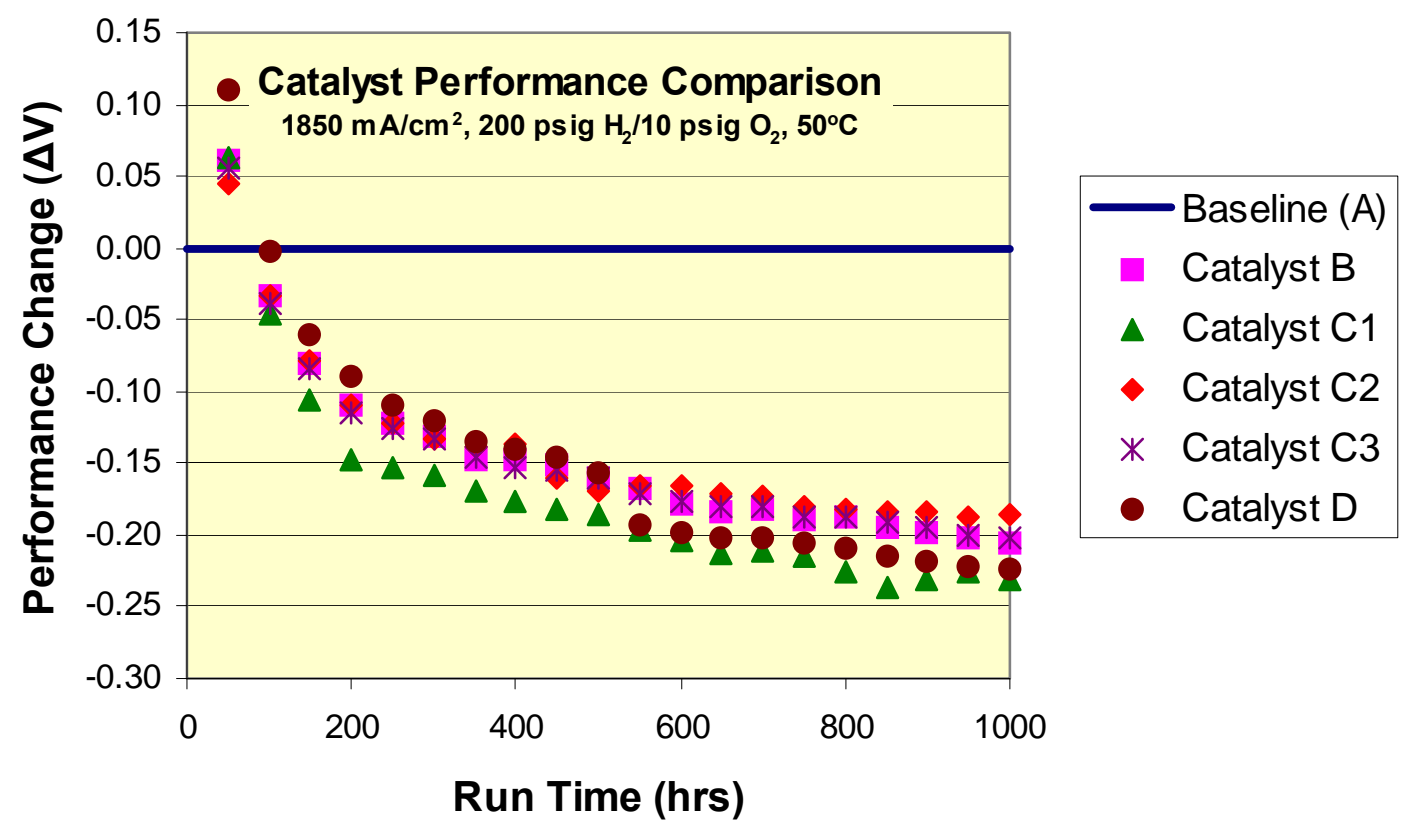

Figure 5.5-1: Catalyst Duration Testing Performance Comparison

The testing indicated that all of the alternative catalyst samples performed significantly better than the baseline. Voltage improvements of 180 to $230 \mathrm{mV}$ were observed for all cases. This represents a voltage efficiency increase of 6-8\% over the current baseline electrolyzer performance. The order of performance improvement was as follows:

$$
\mathrm{C} 1>\mathrm{D}>\mathrm{B}=\mathrm{C} 3>\mathrm{C} 2>\mathrm{A} \text { (Baseline). }
$$

Interestingly, there was no correlation observed between catalyst surface area and overall performance, indicating that the activity of the catalyst was more dependent on the type of material than the active area of the material. This does leave open the possibility of improving the surface area of the most active materials in order to gain even more performance improvements.

\section{Conclusions}

It was found that catalyst Sample C1 performed the best, slightly better (5-10 $\mathrm{mV}$ ) than Catalyst Sample D and 30-40 mV better than the other catalysts. Overall, these performance differences were minor compared to the baseline and any one of these catalysts represents a significant performance benefit versus the baseline catalyst material. Taking into account the process-ability analysis, Catalyst Sample C1 would appear to be the best choice due to its performance improvement combined with its enhanced processing improvement. Use of this catalyst should result in the highest level of improvement in performance and cost. 


\section{Hydrogen Generation From Electrolysis}

\subsection{Evaluation of Lower Cost / Higher Performance Ion Exchange Membranes}

The ion exchange membrane is one of the most critical components of the PEM electrolyzer. The ionomer used in these membranes is a very specialized material, which allows ionic conduction while preventing electronic conduction. The ionomer currently used for these specialized functions is expensive. One way to reduce the cost of the membrane is to make it thinner, thereby significantly decreasing the amount of material used. Reducing the thickness also decreases the distance that protons must travel through the membrane, which has a direct impact on cell efficiency. Manufacturability and durability are of major concern when using thinner membrane material. Thinner membranes are generally less tolerant to particle contamination and can be more difficult to handle and process. This study evaluated the manufacturability, electrochemical performance and durability of a thinner membrane material and compared the results to the baseline material.

\section{Experimental Setup}

A membrane material that was 30\% thinner than the baseline membrane was evaluated in this study. The material had similar chemical and physical properties as the baseline membrane; however, it cost approximately $25 \%$ less.

The evaluation of the alternative membrane material included the following:

1. MEA Manufacturability

2. Cross-MEA Resistance

3. Electrochemical Performance

4. Chemical Stability / Durability

The membrane material was processed into an MEA using Proton's proprietary commercial MEA fabrication process. The operator was instructed to note any handling or processing differences between the alternative and baseline membrane that would impact the MEA manufacturing process. The cross-MEA resistance was measured using the aforementioned test fixture and procedure. The electrochemical performance of the alternative membrane material was evaluated in a commercial 20-cell, electrolyzer cell stack configuration. Alternative catalyst B, the previously tested high performance catalyst, was used to fabricate the MEAs in this stack. Alternative catalyst B was used instead of C1 due to availability constraints.

The stack was run using a modified commercial Hogen ${ }^{\mathrm{TM}} 40$ system at the following operating conditions:

\begin{tabular}{|c|c|}
\hline Operating Temperature: & $30-50^{\circ} \mathrm{C}$ \\
\hline Operating Current Density: & $1615 \mathrm{~mA} / \mathrm{cm}^{2}$ \\
\hline Operating Pressure: & 0 - 200 psig $\mathrm{H}_{2} / 10$ psig $\mathrm{O}_{2}$ \\
\hline
\end{tabular}

\section{$\underline{\text { Results }}$}

The thinner membrane was slightly more difficult to manufacture into MEAs than the current membrane material. The material was more prone to tearing than the baseline 


\section{Hydrogen Generation From Electrolysis}

material and special care had to be taken when it was handled. Unless manufacturing processes are enhanced, it is likely that scrap levels would be higher with the thinner membrane material than the current baseline. The results of the cross-MEA resistance measurements were normalized to that of the baseline and are shown in Table 5.6-1.

Table 5.6-1: Comparison of Cross-MEA Resistance

\begin{tabular}{|ccc|}
\hline Sample & $\begin{array}{c}\text { Relative Cross-Cell MEA } \\
\text { Resistance }(\mathbf{m O h m})\end{array}$ & Total MEA Cost Savings \\
Baseline MEA & 1.0 & - \\
Alternative MEA & 0.8 & $33 \%$ \\
\hline
\end{tabular}

The difference in cross-MEA resistance between the baseline MEA and the low cost MEA is largely due to the difference in membrane thickness. This decrease in MEA resistance is responsible for some of the performance gains shown in Figure 5.6-1 below. The total MEA cost savings shown in 5.6-1 accounts for the savings realized from the thinner membrane and the lower cost catalyst.

The electrochemical performance of the alternative membrane material vs. the baseline membrane material is shown in Figure 5.6-1. The test stand used to run this stack has less control over the stack operating temperature than the 3-cell R\&D test stands used in other tests done on this project. In order to reduce this variability, the data shown in Figure 5.6-1 has been temperature-corrected to $50^{\circ} \mathrm{C}$.

\section{MEA Performance Comparison}

$\left(1,615 \mathrm{~mA} / \mathrm{cm}^{2}, 200 \mathrm{psi}_{2}, 10 \mathrm{psi}_{2}, 50^{\circ} \mathrm{C}\right)$

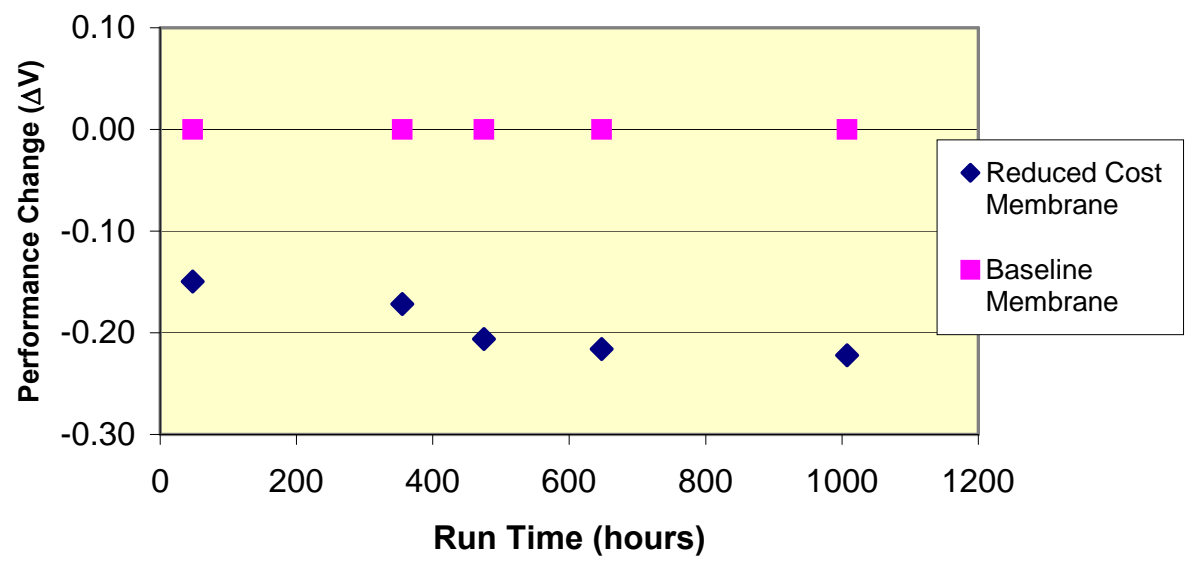

Figure 5.6-1: Reduced Cost MEA Performance Comparison

In general, the reduced-cost MEAs performed significantly better than the baseline MEAs. The difference between the two MEAs during the first few hundred hours of operation is most likely due to the thinner membrane material used in the reduced-cost MEA. The further improvement in performance after several hundred hours of operation can be attributed to the activity difference of alternative catalyst B. (See Evaluation of 


\section{Hydrogen Generation From Electrolysis}

Lower Cost / Higher Performance Catalyst Study.) The long-term durability of the thinner membrane material was not fully evaluated; however, no durability issues were observed after the first 1,000 hours of operation. At least ten thousand hours of operation will be necessary in order to compare the durability of the thinner membrane material to that of the baseline.

\section{Conclusions}

This study showed that MEAs made with lower cost membrane and catalyst material showed a significant improvement in electrochemical performance and a 33\% reduction in cost over the baseline MEA. The performance benefit could translate to higher current density operation or a reduction in catalyst loading, either of which would be a further cost savings. The lower cost membrane material could be used in current MEA manufacturing process; however, special care needed to be taken when it was handled. Long-term operation will be necessary in order to compare the durability of this membrane with the baseline material. 


\section{Hydrogen Generation From Electrolysis}

\section{Electrochemical Compression of Hydrogen Study}

\subsection{Background}

One key element affecting the effective usage of hydrogen as an energy carrier is the transport and/or storage of hydrogen gas in sufficient amounts for its intended application since the volumetric energy density of hydrogen is only about a quarter of that of gasoline. In current state-of-the-art hydrogen storage technologies, the storage of hydrogen at high pressure in the gas phase is still the most simple, mature and economical way of storage. Conventional reciprocating or diaphragm hydrogen compressors are often associated with high maintenance due to friction and wear, and the potential of lubricant contaminating the compressed gas. In addition, due to the availability of motor size, conventional compressors often require relatively high hydrogen throughput to be efficient.

A potential alternative to mechanical compressors is the application of a Proton Exchange Membrane (PEM) hydrogen compressor. A major advantage of this alternative is its potential for low maintenance, as it has no moving parts involved in the compression process. Also, because the system only selectively allows hydrogen to migrate across the membrane, the resulting compressed hydrogen is of highest purity, free from other inert gases.

\subsection{Approach}

A dedicated bench-scale test stand designed for a maximum operating pressure of 2,400 psi was built and commissioned for the proof-of-concept electrochemical hydrogen compression tests. The electrochemical compression cell (ECC) consists of single-cell hardware. The membrane electrode assembly (MEA) is Nafion 117-based and has an active area of $27.9-\mathrm{cm} 2(0.03-\mathrm{ft} 2)$. Humidification is accomplished by passing the hydrogen gas through Nafion tubing submerged inside of a stainless steel water vessel that is heated at controlled temperature. Line heaters and a heating pad on the cell stack body are used to maintain and control system operating temperature. The ECC current is controlled by a power supply. The product pressure is monitored by a pressure transducer and a digital pressure gauge, and is regulated via a backpressure regulator. Moisture content in the pressurized product stream is removed in a desiccant column and the dried product flow rate is measured by a mass flow meter. Due to the operating range of the mass flow meter, product flow rates below range were measured by bubble displacement technique. All of the pertinent system operating parameters were captured by a data logging system. A schematic of the test stand is shown in Figure 6.2-1.

Comprehensive testing was carried out to determine the interrelationships between the key parameters affecting electrochemical compression, including humidification levels, hydrogen stoichiometries, cell voltage potentials during the pressure increase, hydrogen capacity, product pressure and energy requirement for the compression work. 


\section{Hydrogen Generation From Electrolysis}

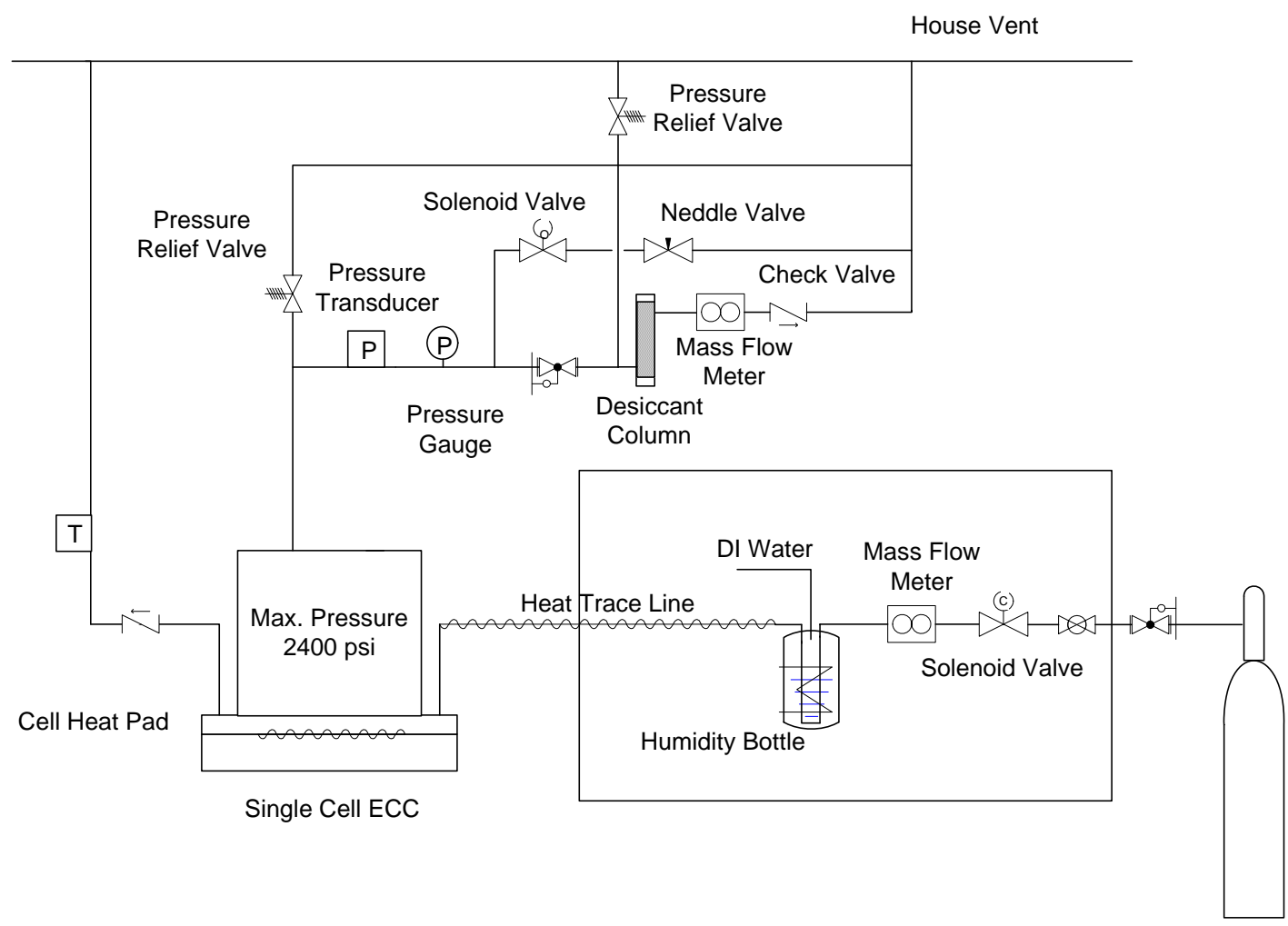

Figure 6.2-1: Schematic Of The Electrochemical Hydrogen Compressor Test Stand

\subsection{Results and Discussion}

Humidification of the hydrogen inlet is necessary to provide good ionic conductivity and to avoid dehydration of the MEA during the electrochemical compression process. However, over humidification and water condensate buildup at the cathode side of the cell could lead to cell voltage instability, rendering the process inoperable. Initial testing was carried out at four humidification levels (15\%, 40\%, 60\% and 100\% R.H.) at ambient inlet pressure and $60^{\circ} \mathrm{C}$ operating cell temperature to determine the required humidification level for the electrochemical compression cell operation. The results shown in Figure 6.3-1 indicate that humidification levels at $60 \%$ to $100 \%$ R.H. are required for stable performance. At levels below 60\% R.H., cell voltage became unstable as the current density increased.

The sensitivity of hydrogen inlet flow rate on electrochemical compression was evaluated at two stoichiometries. As shown in Figure 6.3-2, at a compressed pressure of 1.7-MPa (250 psi), the cell voltages were almost identical at stoichiometric ratios of 1.0 and 1.25. The results from this test also indicated that the capacity of the electrochemical compression is dependent on the operating current density, and the conversion from the feed hydrogen is less than that of the stoichiometric amount. 


\section{Hydrogen Generation From Electrolysis}

Based on the humidification and hydrogen stoichiometry test results, all subsequent compression tests conditions were set at 100\% R.H. humidification and hydrogen feed at 1.0 stoichiometry.

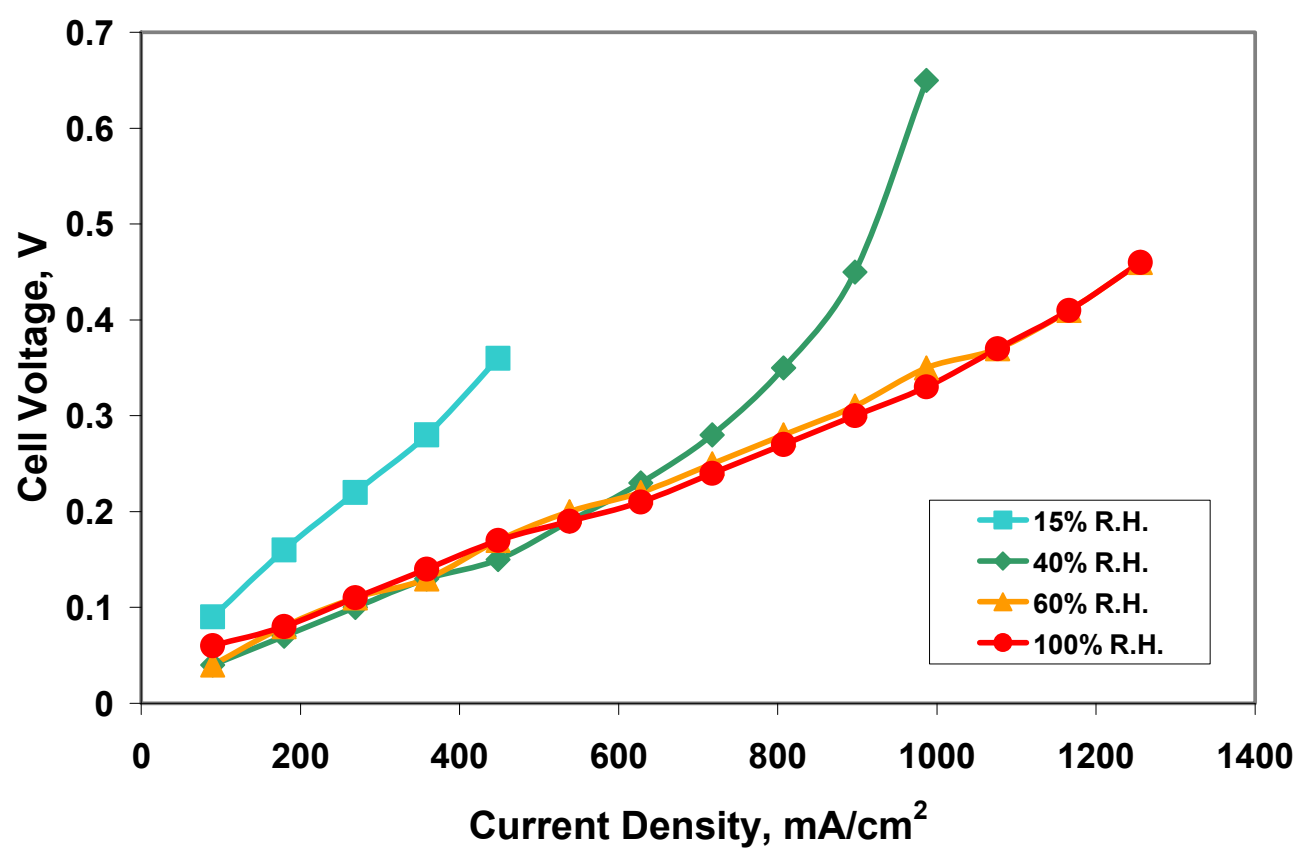

Figure 6.3-1: The Effect of Humidification On Electrochemical Compression Cell

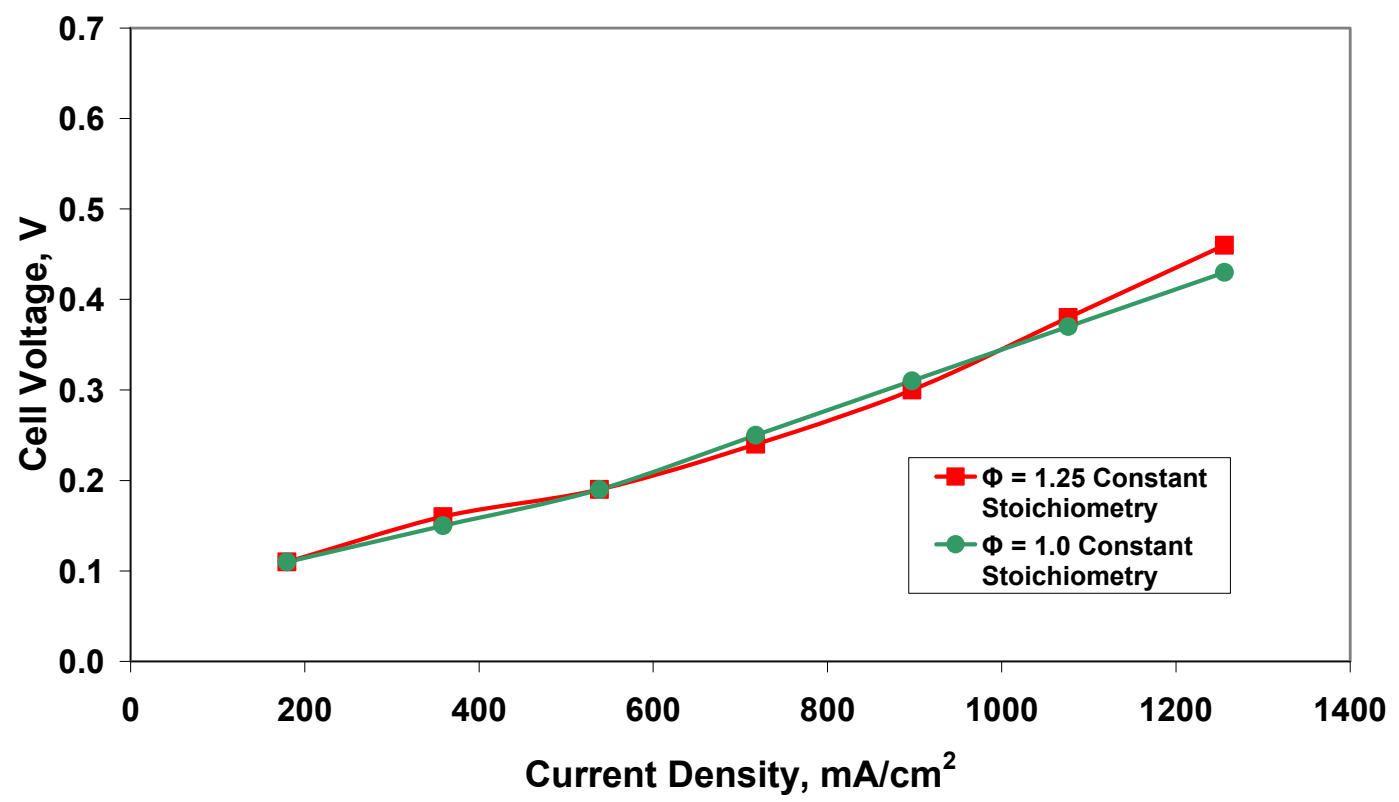

Figure 6.3-2: The Effect of Hydrogen Stoichiometry On Cell Voltage 


\section{Hydrogen Generation From Electrolysis}

The polarizations of the electrochemical compression cell at product pressures of 1.7-, 6.9-, 10.3-, 13.8-, and 16.5-MPa (250-, 1,000-, 1,500-, 2,000-, and 2,400-psi) are shown in Figure 6.3-3. As expected, the cell voltage increased with increased product pressure, reflecting more energy is required to compress the same amount of hydrogen to a higher pressure. The increment was proportionally larger at a higher current density. To verify the validity of these results, the equilibrium Nernst potentials at various pressures were calculated and plotted against the measured voltages as shown in Figure 6.3-4.

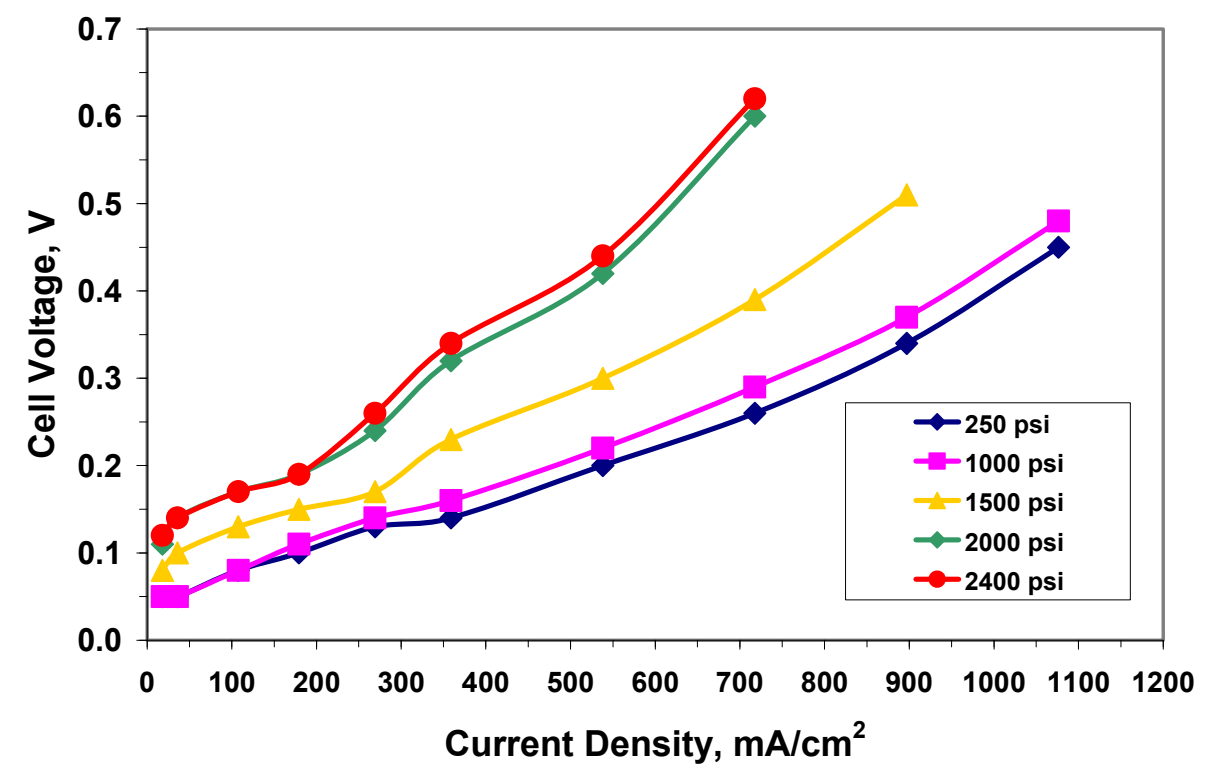

Figure 6.3-3: Polarization of the electrochemical compression cell at various pressures

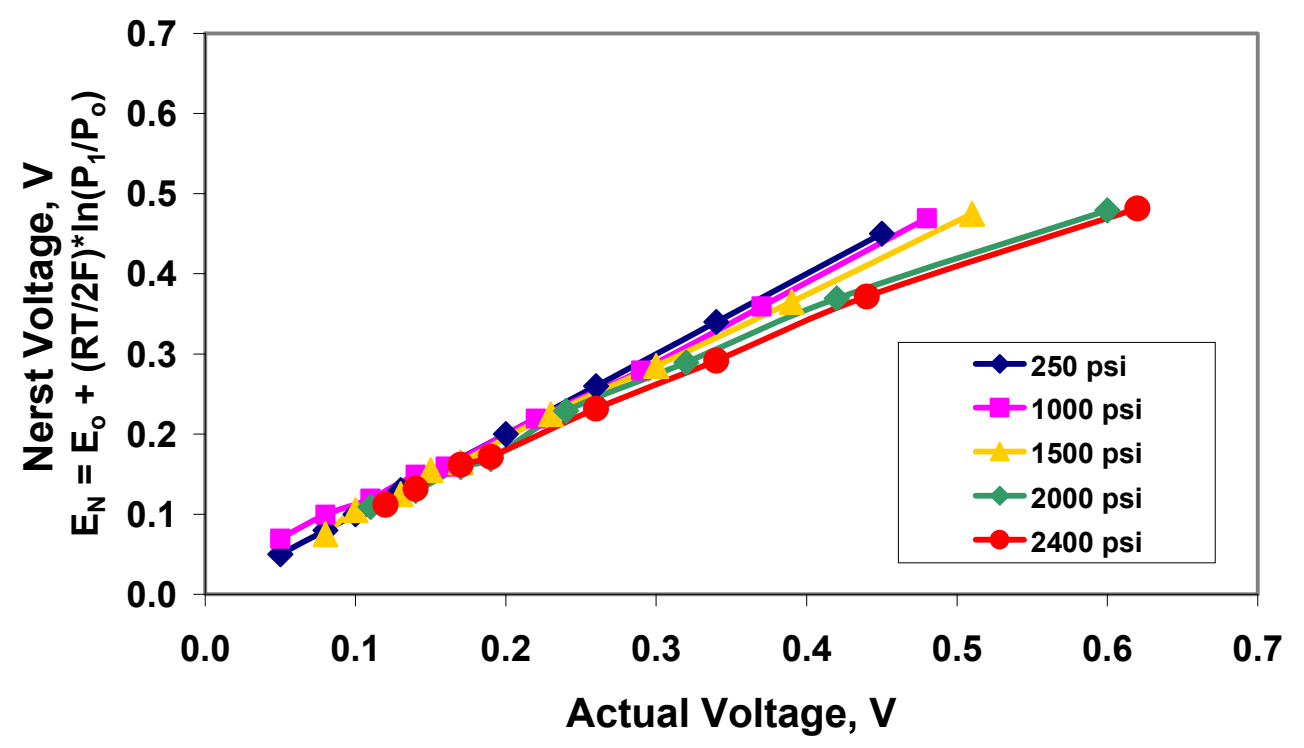

Figure 6.3-4: Comparison between the measured and calculated cell voltages 


\section{Hydrogen Generation From Electrolysis}

At low current densities ( $<200 \mathrm{~mA} / \mathrm{cm} 2$ ) the voltage differences are small, but at higher current densities the difference are more significant. The measured voltages were larger than those predicted by the Nernst potentials. This is attributed to the increased resistance of the cell (Figure 6.3-5). Because of the difference in pressure between the anode and cathode, contraction and expansion of the materials inside the cell result in increases of the contact resistance and therefore the higher voltages. Optimizing the hardware packaging of the electrochemical cell will minimize this artifact.

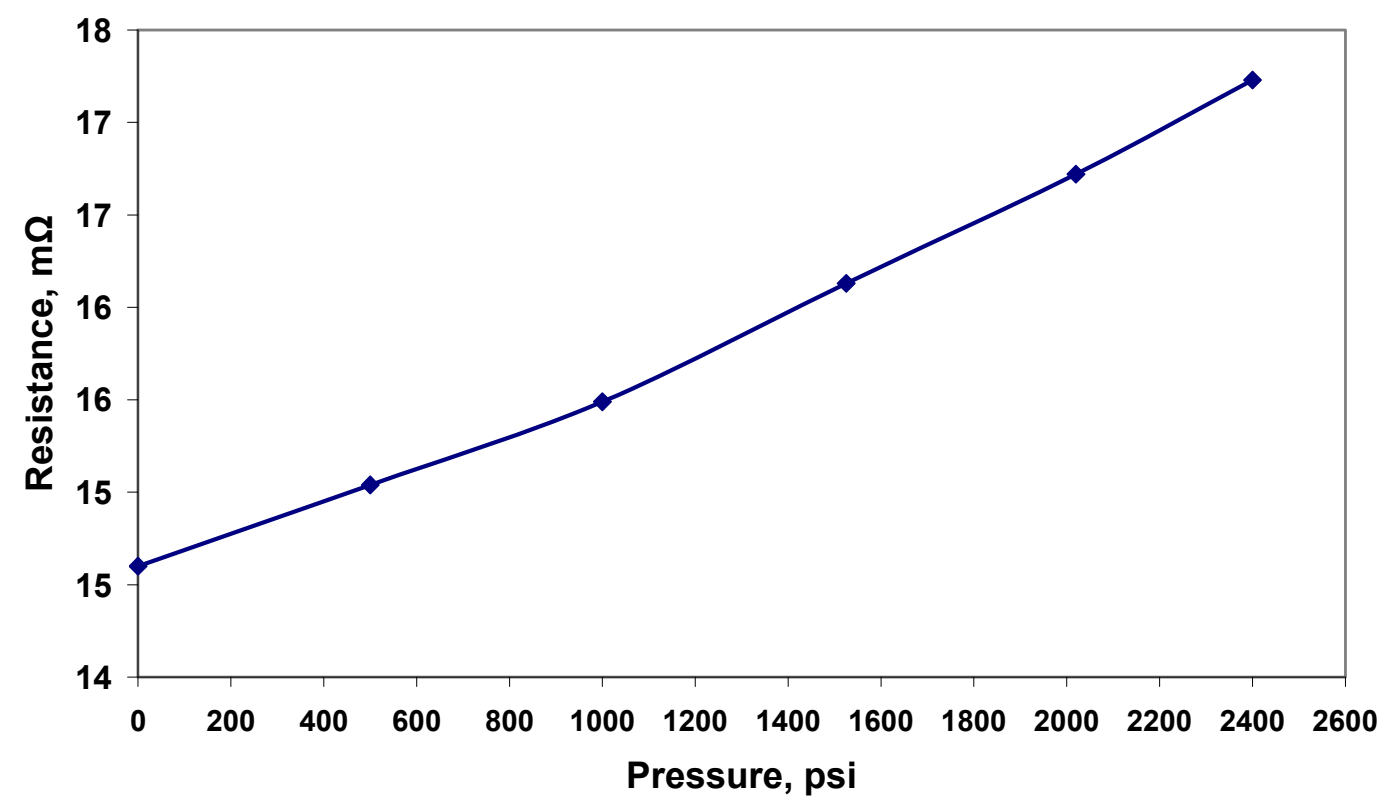

Figure 6.3-5: Contact resistance of the electrochemical compression cell at various pressures

The compressed hydrogen capacity of the electrochemical compression cell relative to the current density and pressure is shown in Figure 6.3-6. For the purpose of these experimental test runs, the portion of hydrogen feed that was not compressed was vented off. Data indicates that high throughput of hydrogen is feasible even at modest current densities. The resulting hydrogen feed utilization ranged from $80 \%$ to $95 \%$, at 718 $\mathrm{mA} / \mathrm{cm}^{2}$ to $1076 \mathrm{~mA} / \mathrm{cm}^{2}$. Although hydrogen permeation increased as product pressure increased (Figure 6.3.7), the high hydrogen conversions reflect that it did not significantly affect the PEM compression efficiency. 
Hydrogen Generation From Electrolysis

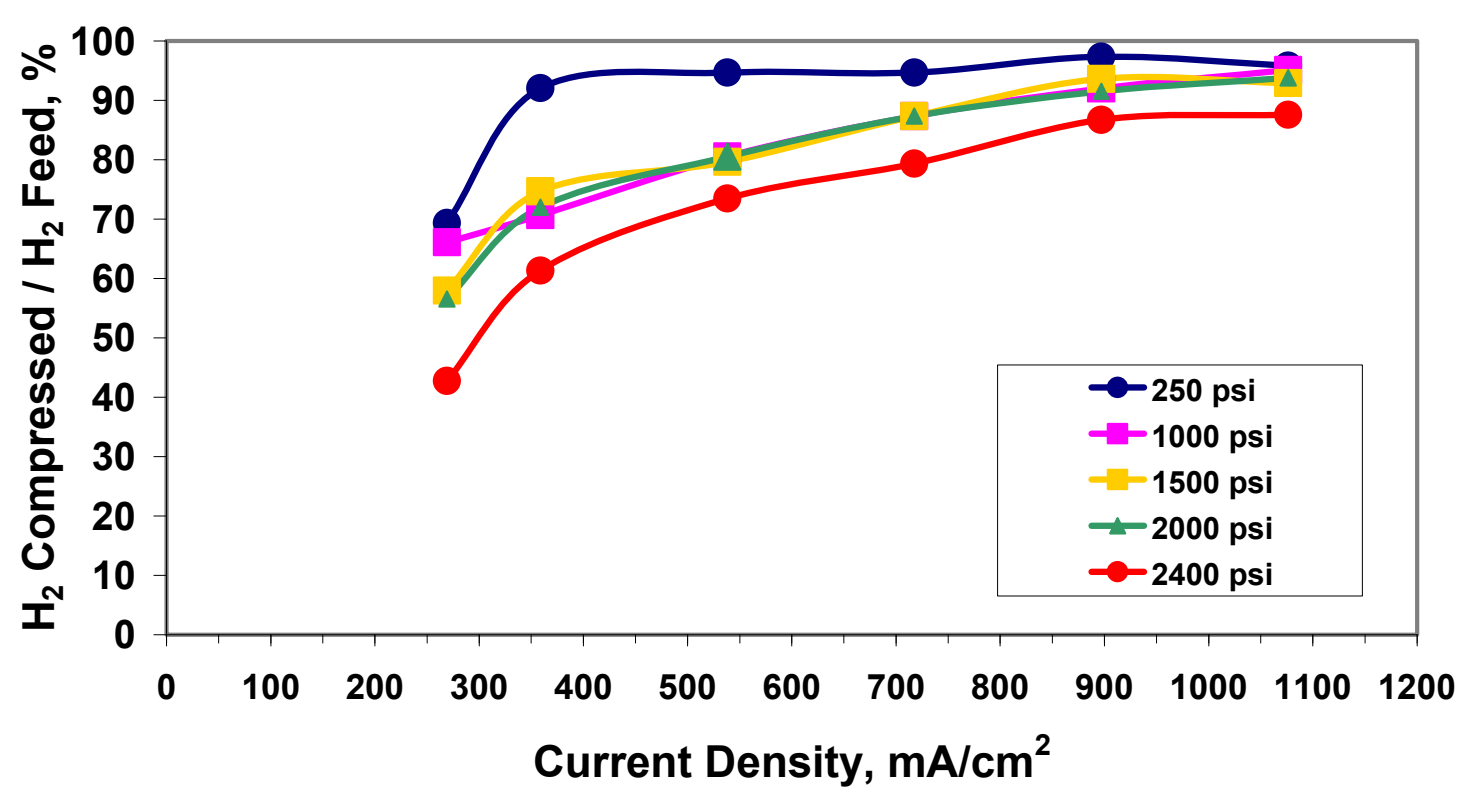

Figure 6.3-6: Compressed Hydrogen Conversion Efficiencies

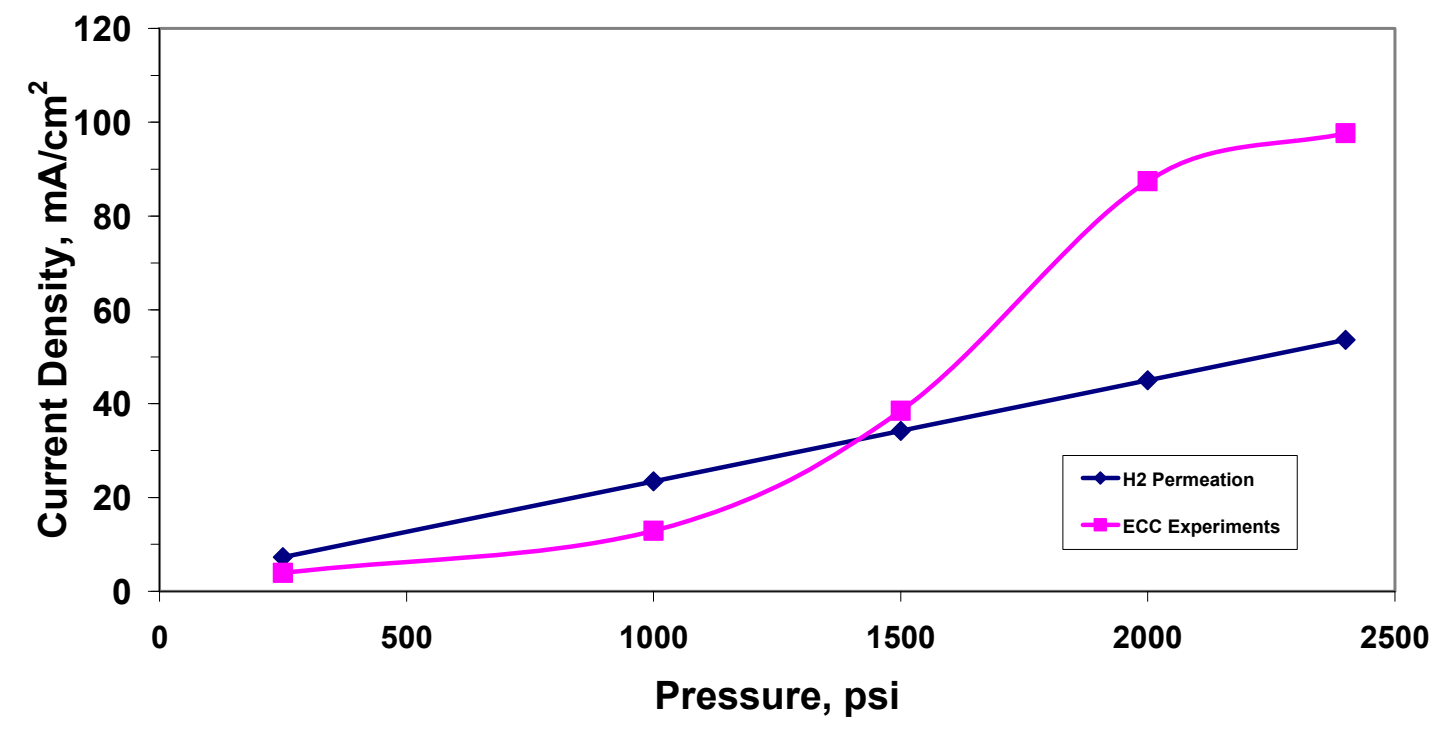

Figure 6.3-7. Relationship Between Hydrogen Permeation Losses And Compression Pressures

The energy consumption by hydrogen electrochemical compression along with field data from a single-stage diaphragm compressor is shown in Figure 6.3-8. The results show that at current densities below $718 \mathrm{~mA} / \mathrm{cm}^{2}$, with over $85 \%$ hydrogen feed utilization, electrochemical compression can be comparable or slightly more energy efficient than that of the single-stage diaphragm compressor at compression ratio of 30. 


\section{Hydrogen Generation From Electrolysis}

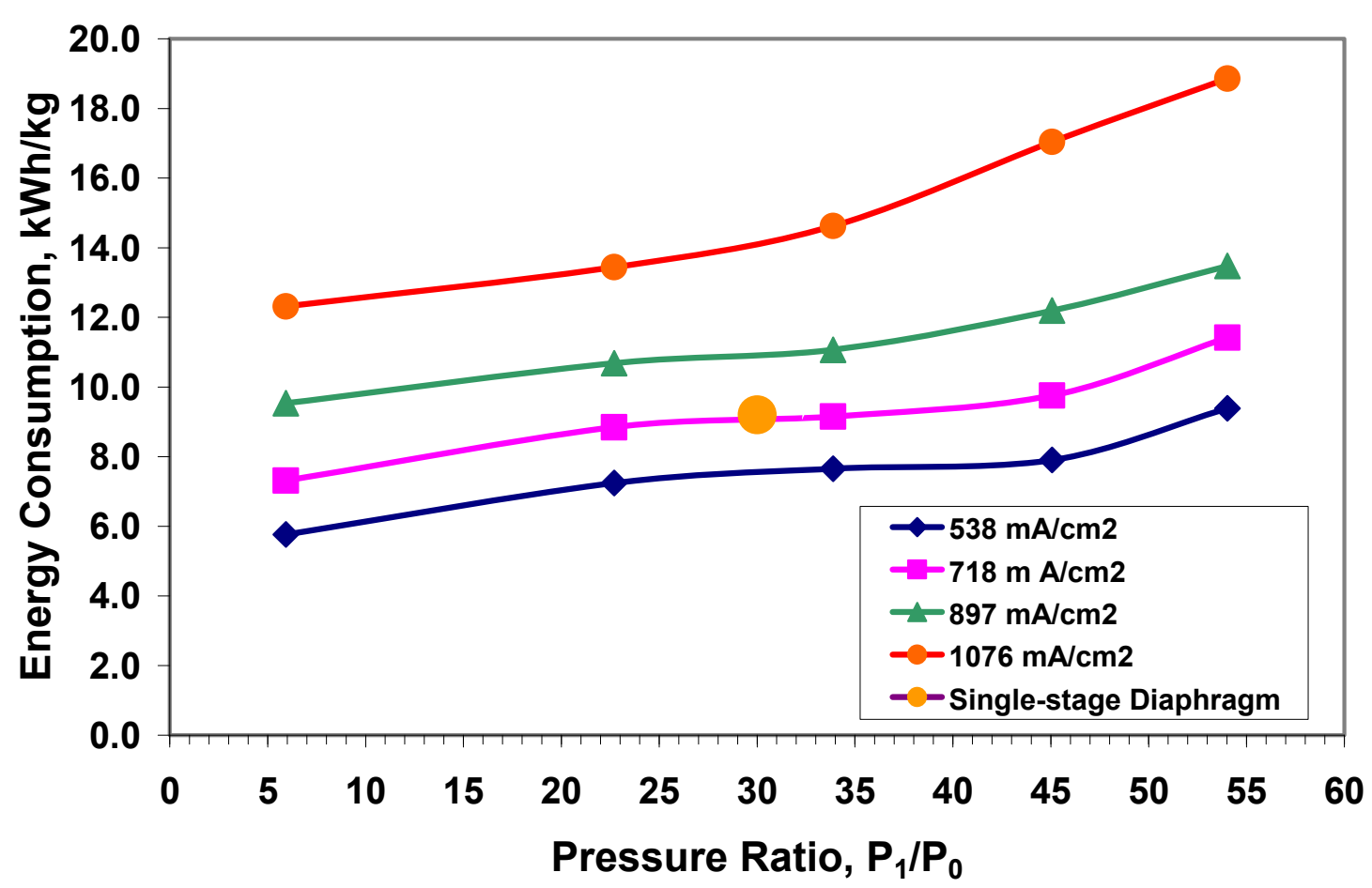

Figure 6.3-8. Energy consumption by hydrogen electrochemical compression

\subsection{Conclusions}

The experimental data demonstrated that the electrochemical compression of hydrogen is technically feasible as an alternative or supplement to mechanical compression. High hydrogen feed utilization at relatively high current densities indicates that hydrogen throughput can be flexible by stacking the appropriate number of cells for the application. Although the electrochemical compression performance was not significantly affected for the pressure range tested (up to 2,400 psi), the limiting factors to the high pressure compression are mechanical cell hardware, cell internal resistance and hydrogen back diffusion.

Several aspects of electrochemical compression deserve further study and characterization. The initial tests were performed using small, un-optimized single cell electrolyzer hardware. The next step should be the test of single cell hardware designed specifically for hydrogen compression. Once the operational parameters of the compression cell are identified and optimized, scale up of capacity via larger cell area and/or multiple cells deserve study. 